\title{
Análise do sistema de controle interno no Brasil: objetivos, importância e barreiras para sua implantação
}
Internal control system analysis in Brasil: objetives, importance and hinders to its implementation

Análisis del sistema de control interno em Brasil: objetivos, importanica y barreras para su aplicación.

\section{Renato Pereira Monteiro}

Doutorando em Contabilidade na Universidade de Aveiro e Universidade do Minho em

Portugal

Contador do Instituto Federal do Rio Grande do Sul - IFRS

Endereço: Rua Coronel Vicente, $n^{\circ}$ 281, Bairro Centro Histórico

CEP: 90030-9041 - Porto Alegre/RS - Brasil

E-mail: renatomonteir@gmail.com

Telefone: +55 (51) 3930-6006

Artigo recebido em 11/11/2014. Revisado por pares em 20/02/2015. Reformulado em 30/03/2015. Recomendado para publicação em 20/04/2015 por Sandra Rolim Ensslin (Editora Científica). Publicado em 29/05/2015. 


\title{
Resumo
}

Parte-se da premissa de que o controle interno é importante no contexto das organizações públicas e tem-se por objetivo realizar uma análise das suas finalidades e importância na administração pública do Brasil e das barreiras para sua implantação. A estratégia de pesquisa desenvolvida é uma revisão sistemática da literatura e a realização de pesquisa documental em relatórios do TCU e da CGU. Identificou-se um conjunto de onze objetivos para atuação do SCI. Os resultados apontam também para uma categorização da importância do SCI no contexto do setor e as principais barreiras para sua implantação. Um quadro teórico de cinco categorias de importância do SCI foi constituído gestão do risco, informação, comportamento ético, imagem da entidade e proteção dos recursos públicos. As principais barreiras detectadas foram a falta de uma cultura de gestão ao risco, a carência de pessoal em número adequado e a qualidade técnica exigida.

Palavras-chave: Sistema de controle interno. Importância. Objetivos. Barreiras.

\begin{abstract}
Part on the assumption that the internal control is important in the context of public organizations and has aimed to carry out a review of its purposes and importance in public administration in Brazil and the barriers to its implementation. The search strategy developed is a systematic literature review and conducting documentary research reports on TCU and CGU. Identified a set of eleven goals for performance of SCI. The results also point to a categorization of the importance of SCI in the context of the sector and the main barriers to its implementation. A theoretical framework of five categories of importance of SCI was established risk management, information, ethical behavior, body image and protect public resources. The main barriers identified were the lack of a culture of risk management, the shortage of personnel in adequate numbers and with the required technical quality.
\end{abstract}

Keywords: Internal control system. Importance. Goals. Barriers.

\section{Resumem}

Parte del supuesto de que el control interno es importante en el contexto de las organizaciones públicas y ha tratado de llevar a cabo una revisión de sus objetivos y la importancia en la administración pública en Brasil y las barreras a su implementación. La estrategia de búsqueda desarrollada es una revisión sistemática de la literatura y la realización de informes de investigación documental sobre TCU y CGU. Identificado un conjunto de once metas para el desempeño de la lesión medular. Los resultados también apuntan a una categorización de la importancia de la lesión medular en el contexto del sector y las principales barreras para su implementación. Un marco teórico de las cinco categorías de importancia de la lesión medular se estableció la gestión de riesgos, la información, el comportamiento ético, la imagen corporal y proteger los recursos públicos. Las principales barreras identificadas fueron la falta de una cultura de gestión de riesgos, la escasez de personal en número suficiente y con la calidad técnica requerida.

Palabras clave: Sistema de control interno. Importancia. Objetivos. Barreras 


\section{Introdução}

Os escândalos corporativos das últimas décadas têm aumentado a relevância da contabilidade, das auditorias (interna e externa) e dos controles internos. Segundo Vinnari e Skaerbaek (2014), as exigências sociais para as organizações demonstrarem um controle interno apropriado têm aumentado a importância das auditorias e da contabilidade, revitalizando seu papel na gestão do risco. Destacam que as falências de empresas e escândalos que ocorreram no Reino Unido e nos EUA, no início de 2000, levantaram suspeitas de que a auditoria não é suficiente para evitar fraudes e precisa ser complementada pelo Sistema de Controle Interno - SCI e pela gestão do risco, resultando em uma governança eficaz. Os controles internos ganham mais relevância em todos os segmentos e tipos de entidade, conforme o volume de negócio e recursos envolvidos (PEREIRA, 2009). A importância de bons procedimentos de governança corporativa e de controles internos tem sido enfatizada por uma série sucessiva de relatórios sobre a necessidade de sistemas adequados para a gestão e o controle das organizações (DALGLEISH; COOPER, 2005), (WOOD, 2009).

O controle interno, no contexto das organizações privadas no Brasil, já foi abordado por Pereira (2009), Lélis e Mário (2009), Roncálio, Alberton, Amaral (2009), Farias, Luca e Machado (2010) e Oliveira (2011). Quanto a aspectos do controle interno na administração pública, encontram-se estudos como os de Davis Blascheck (2006), Siena e Soares (2009), Azevedo, Ensslin e Reina (2011), Albuquerque (2011) e Cavalcante, Peter e Machado (2013).

No setor público onde a preocupação com o bom uso dos recursos públicos, seguir princípios de regulação e legalidade são exigências cotidianas, a preocupação com os controles internos como forma a apoiar os gestores da missão de administrar, subsidiar o controle externo e fomentar o controle social deve estar incorporada à realidade do setor de forma ampla. O conceito de controle interno é percebido como algo mais amplo do que uma simples função da administração. Farias, Luca e Machado (2010, p. 57) afirmam que, na atualidade, o controle é "um sistema de controle ou simplesmente controles internos, sendo definitivamente introduzido nas pesquisas acadêmicas e também no mundo dos negócios como ferramenta de gestão empresarial".

Para Sarens, Vissher e Van Gils (2010), o controle interno, no setor público, possui singularidades específicas e deve ser compreendido no contexto de atuação dessas organizações, listando uma série de requisitos que devem ser observados para a análise do controle interno no setor: (1) o seu foco no cumprimento dos objetivos sociais ou políticos; (2) o uso de recursos públicos; (3) a importância do ciclo de orçamento; (4) a complexidade do seu desempenho (que requer um equilíbrio entre os valores tradicionais, como a legalidade, integridade e transparência e os valores modernos, gerenciais como a eficiência e eficácia); e (5) o amplo escopo de sua responsabilidade pública.

A administração pública brasileira seguidamente é criticada em relação a sua capacidade de atingir seus objetivos, de cumprir suas políticas públicas e implantar programas e serviços com qualidade, eficácia e eficiência, que gerem retorno para a sociedade (TCU, 2009). Segundo Cavalheiro e Flores (2007, 21), "os administradores necessitam de informações, porém muitas vezes elas não existem" ou sua formatação, quando existe, é inadequada ou é recebida pelos gestores de forma tardia. José Filho (2008, p. 98) que fez pesquisa bibliográfica sobre a importância do Sistema de Controle Interno - SCI no setor 
relata que sua pesquisa "evidenciou a necessidade da presença efetiva do Controle Interno na Administração Pública, que juntamente com a Auditoria Interna, constituem-se em ferramentas indispensáveis no combate ao desvio de conduta e ao erro [...]". Esses argumentos reforçam a premissa de que o controle interno é importante para o setor público.

Essa premissa dá suporte ao objetivo do estudo: realizar uma análise dos objetivos e da importância do controle interno no setor público no contexto brasileiro e das barreiras para sua implantação. A estratégia de pesquisa desenvolvida é uma revisão sistemática da literatura sobre o tema e a realização de pesquisa documental em relatórios do Tribunal de Contas da União do Brasil - TCU e da Controladoria Geral da União - CGU. A contribuição teórica do estudo é constituir um quadro teórico dos principais objetivos do controle interno, de sua importância e barreiras para implantação no contexto público, e avança nos estudos já realizados nesse sentido, fazendo a triangulação entre a legislação e os normativos em vigor, a literatura que aborda o tema e os relatórios do TCU e da CGU.

O estudo é estruturado em mais quatro seções: revisão da literatura, metodologia, apresentação e análise dos dados e conclusão. A revisão da literatura foi desenvolvida de forma a evidenciar como o controle interno é organizado no Brasil e quais são seus principais objetivos; a metodologia apresenta a forma como o estudo foi desenvolvido e suas características, como abordou-se o problema e os passos seguidos para atingir o objetivo do estudo. $\mathrm{Na}$ análise e apresentação dos dados, estão os resultados da revisão sistemática da literatura e da pesquisa documental.

\section{Revisão da Literatura}

\subsection{Controle Interno}

É importante partir do entendimento de que controle interno, controles internos e sistema ou estrutura de controle(s) interno(s) são expressões com a mesma abordagem finalística, são sinônimos que têm como objetivo fazer referência ao processo composto pelo conjunto de políticas, pelas regras de estrutura organizacional e pelos procedimentos adotados dentro da entidade para vigiar, fiscalizar e verificar, que permite criar mecanismos de correção, prevenção, direção e observação para eventos que possam impactar no alcance dos objetos da organização (TCU, 2009). Portanto, é um processo de responsabilidade da gestão da entidade que o adota no intuito de assegurar uma margem de garantia quanto ao atingimento desses objetivos.

Controle, no entender de Imoniana e Nohara (2005, p. 38), “é um importante elemento das funções administrativas de uma organização, pois permite a constante avaliação do alcance dos objetivos estratégicos e operacionais". Os autores destacam que sua implantação permite amenizar e reduzir gargalos que impedem a entidade de atingir seus objetivos. Franco e Marra (1991, p. 207) alinham com esse entendimento de que são os instrumentos da organização destinados à vigilância, fiscalização e verificação que permitem prever, observar, dirigir ou governar os acontecimentos que se verificam dentro da entidade e que produzam reflexos em seu patrimônio.

Para o INTOSAI (2004), é um processo integrado realizado pela gestão da entidade, projetado para lidar com os riscos e oferecer garantias de que a missão da entidade será cumprida, buscando atingir objetivos éticos, eficiência e eficácia operacional e econômica. 
Outra definição relevante de SCI para este estudo é o especificado pelo COSO (2013) que o define como um processo conduzido pela estrutura de governança, administração e outros profissionais da entidade, e desenvolvido para proporcionar segurança razoável com respeito à realização dos objetivos relacionados a operações, divulgação e conformidade.

O Departamento do Tesouro Nacional do Brasil (1991), por sua vez, por meio da Instrução Normativa $\mathrm{n}^{\mathrm{o}}$ 16, de 20 de dezembro de 1991, traz o conceito de controle interno como sendo o conjunto de atividades, planos, métodos e procedimentos interligados utilizado a fim de assegurar que os objetivos dos órgãos e das entidades da administração pública sejam alcançados de forma confiável e concreta, evidenciando eventuais desvios ao longo da gestão, até a consecução dos objetivos fixados pelo Poder Público.

Marçola (2014) corrobora esse conceito, afirmando que é uma ação traçada por pessoas que fazem a gestão da organização em busca de diminuir riscos e de aumentar as chances de atingir os objetivos; quando aplicado, a administração pública deve assegurar que as ações estejam calçadas ainda pelos princípios constitucionais da legalidade, impessoalidade, moralidade, publicidade e eficiência.

Portanto, ao aplicarmos o controle interno no setor público, deve-se perceber sua significância para a gestão como elemento de segurança, não só de redução de riscos, mas de apoio ao cumprimento de uma série de princípios, regulamentos e normas que o setor público se sujeita. Atualmente, no contexto do Brasil, o SCI, conforme a Norma Brasileira de Contabilidade - NBC T 16.8, editada pelo Conselho Federal de Contabilidade - CFC, é o conjunto de recursos, métodos, procedimentos e processos adotados pela entidade do setor público, com a finalidade de (a) salvaguardar os ativos e assegurar a veracidade dos componentes patrimoniais; (b) dar conformidade ao registro contábil em relação ao ato correspondente; (c) propiciar a obtenção de informação oportuna e adequada; (d) estimular adesão às normas e às diretrizes fixadas; (e) contribuir para a promoção da eficiência operacional da entidade; e (f) auxiliar na prevenção de práticas ineficientes e antieconômicas, erros, fraudes, malversação, abusos, desvios e outras inadequações. Dessa forma, os objetivos macro do SCI estão centrados nesse Normativo. Esses objetivos referenciados pelo CFC, por meio da norma, remetem para a necessidade de uma estrutura organizacional e legal que é tratada na seção seguinte.

\subsection{Organização do SCI no Brasil}

O Brasil é organizado pelos três Poderes: Executivo, Legislativo e Judiciário, que devem atuar de forma harmônica e independente. Sua divisão entre Estados é indissolúvel, nos termos da própria Constituição Federal. Nesse sentido, cada Estado- Membro possui uma autonomia legal com prerrogativas específicas estabelecidas na Constituição. Esse conjunto de leis também regra e disciplina a organização e o funcionamento do SCI, sua obrigatoriedade e vinculação às atividades de apoio ao controle externo. A Constituição tratou de estabelecer a obrigatoriedade do SCI em três dispositivos nos arts. 31, 70 e 74. O art. 31 trata do SCI e sua vinculação ao Poder Executivo, mas como forma de apoio ao exercício do controle externo de competência do Poder Legislativo "Art. 31. A fiscalização do Município será exercida pelo Poder Legislativo Municipal, mediante controle externo, e pelos sistemas de controle interno do Poder Executivo Municipal...". Já o art. 70 trata de sua abrangência em termos de objeto de fiscalização:

Art. 70. A fiscalização contábil, financeira, orçamentária, operacional e patrimonial da União e das entidades da administração direta e indireta, quanto à legalidade, 
legitimidade, economicidade, aplicação das subvenções e renúncia de receitas, será exercida pelo Congresso Nacional, mediante controle externo, e pelo sistema de controle interno de cada Poder.

$\mathrm{O}$ art. 74 estabeleceu que os três Poderes (Executivo, Legislativo e Judiciário) deverão manter de forma integrada o SCI com uma série de finalidade específicas.

A Figura 1 apresenta a abrangência do SCI no Setor Público do Brasil de forma que deve contemplar os três Poderes e as três Esferas (União, Estados e Municípios).

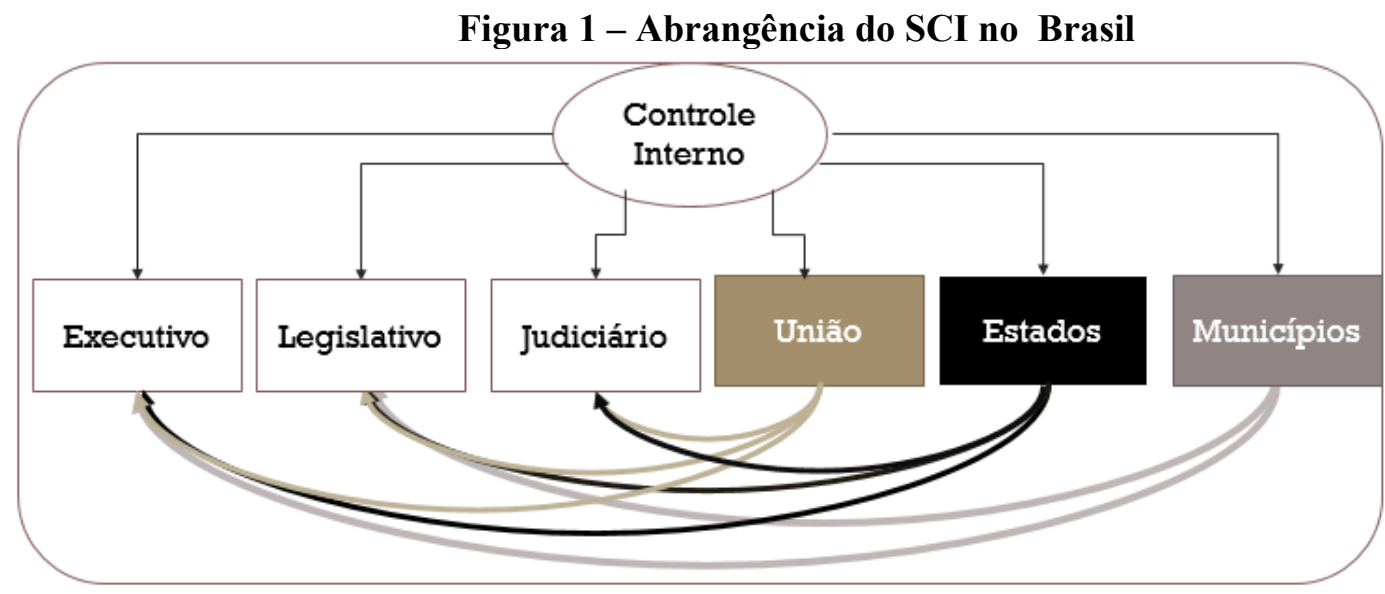

Fonte: Autor (2014).

As finalidades do SCI de cada Poder também foram introduzidas no texto da Lei Complementar n. 101, de 2000, conhecida como Lei de Responsabilidade Fiscal - LRF. Sacramento (2005, p. 33) destaca que a LRF promoveu uma mudança institucional em relação aos cuidados com os recursos financeiros públicos: "Constituindo-se no principal instrumento regulador das contas públicas no Brasil, espera-se que a sua correta aplicação fortaleça o processo de accountability no Brasil", abordando também sua importância para o controle (p. 40) "Consequência natural da transparência e da qualidade das informações, o controle das contas públicas com o advento da LRF foi bastante aprimorado". Na seção seguinte, serão apresentados e discutidos os objetivos do SCI no setor público do Brasil.

\subsection{Objetivos do SCI no Brasil}

Enquanto a Constituição Federal enumerou quatro finalidades para o SCI no contexto público brasileiro, o art. 59 da LRF listou seis finalidades, além de estabelecer que é dever do SCI de cada órgão fiscalizar todos os dispositivos da própria LRF, isto é, primar pela responsabilidade na gestão fiscal de cada órgão e ente da Federação. O Quadro 1 apresenta a lista codificada das finalidades dos dois conjuntos legais, em que CF trata de dispositivos da Constituição Federal, e LFR, de dispositivo da Lei Complementar n. 101. Essa codificação servirá de base para referências futuras no estudo. 


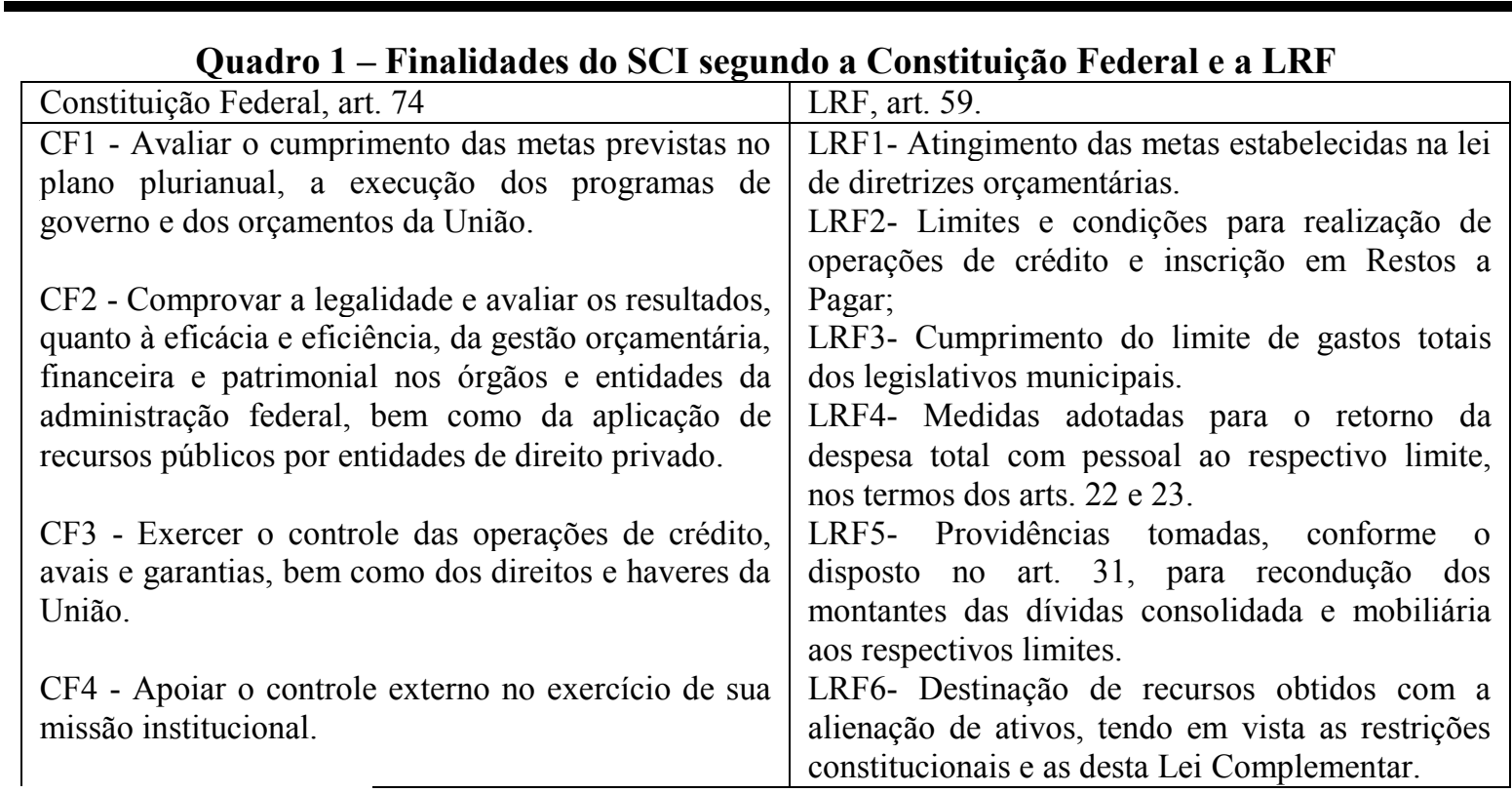

Fonte: Dados da Pesquisa.

Para além dos objetivos estabelecidos no Quadro 1, a NBC T 16.8 também definiu um conjunto de objetivos para o SCI. Esses foram codificados da seguinte forma: (NBC1) salvaguardar os ativos e assegurar a veracidade dos componentes patrimoniais; (NBC2) dar conformidade ao registro contábil em relação ao ato correspondente; (NBC3) propiciar a obtenção de informação oportuna e adequada; (NBC4) estimular adesão às normas e às diretrizes fixadas; (NBC5) contribuir para a promoção da eficiência operacional da entidade; e (NBC6) auxiliar na prevenção de práticas ineficientes e antieconômicas, erros, fraudes, malversação, abusos, desvios e outras inadequações. Destacam-se ainda os objetivos estabelecidos pelo INSTOAI (2004) para o SCI no setor público: (INS1) execução ordenada, ética, econômica eficiente e eficaz das operações; (INS2) cumprimento das obrigações e prestação de contas; (INS3) cumprimento das leis e regulamentos aplicáveis; e (INS4) salvaguarda dos recursos contra mau uso, dano e perdas. Esses também foram codificados para serem comentados na sequência do estudo.

Os objetivos apresentadas no Quadro 1 remetem para uma simetria de elementos entre CF1, LRF 1 que tratam do acompanhamento das metas, ou seja, da gestão do risco no setor público, pode-se interpretar como o risco de não se atingir determinados objetivos e metas estabelecidas no processo orçamental. Estudos como o de Wood (2008) e de Leung e Isaacs (2008) tinham como tema central a gestão de risco na administração pública, reforçando-a como um dos objetivos do SCI.

O objetivo CF2 pode ser desdobrado em vários objetivos específicos: (1) comprovar a legalidade; (2) avaliar os resultados, quanto à eficácia e eficiência da gestão orçamentária, financeira e patrimonial nos órgãos; e (3) avaliar os resultados da aplicação de recursos públicos por entidades de direito privado. Assim, apresenta a preocupação que o SCI deve ter com a legalidade, com a aplicação e com a gestão dos recursos públicos e com o patrimônio das entidades do setor, bem como acrescentar que o SCI deve abranger ainda entidades do setor privado no que tange ao uso de recursos públicos. Percebe-se assim que os objetivos do CF2 atingem a proteção do ativo (avaliar a gestão financeira e patrimonial do órgão) e ainda avaliar os resultados em termos de eficácia e eficiência. Percebe-se que o CF2 alinha-se com 
os objetivos NBC 1, proteção dos ativos, e NBC5 que trata que SCI deve contribuir para a promoção da eficiência operacional da entidade concatenando com o entendimento do INSTOSAI (2004) que o SCI deve primar pela execução ordenada, ética, econômica eficiente e eficaz das operações (NS1).

O CF3 evidencia a preocupação que o SCI deve ter em relação ao passivo público (dívida pública), com o comprometimento dos recursos e com a preservação de seus direitos. Dessa forma, o objetivo LRF2 tem posicionamento semelhante, pois também este objetivo representa a preocupação com o endividamento público. A relação entre o endividamento e a LRF foi estudada por Gerigk, Clemente e Ribeiro (2014, p. 128) ao destacarem que este tema "foi um dos principais pontos abordados pela LRF e por normatizações decorrentes de sua vigência $[\ldots] "$.

O CF4 apresenta uma das mais nobres finalidades do SCI que é apoiar o controle externo no cumprimento de sua missão institucional, como também é percebido por Cavalheiro e Flores $(2007$, p. 17) ao afirmarem que "no que se refere ao controle externo exercido pelos Tribunais de Contas, a primeira e principal finalidade é verificar se o Sistema de Controle Interno municipal está funcionando adequadamente", e justificam esse posicionamento destacando que, com a correta estrutura, podem "subsidiar o administrador com informações e elementos técnicos e também de evitar desperdícios, abusos, fraudes e desfalques, ainda comuns no nosso cotidiano". Conclusão semelhante é apontada por Lima et al. (2014, p. 32): "percebeu-se que o controle externo, representado pelos TC que auxiliam os Poderes Legislativos, desempenha um papel relevante no que diz respeito à concretização do SCI" afirmando que o controle externo orienta e fortifica os controles proporcionando maior transparência nas informações e agilidade na prestação de contas.

Os objetivos LRF 3, 4 e 5 destacam o SCI como fiscalizador da própria LRF, pois os limites que estão estabelecidos nesses incisos tratam de condicionantes apresentados no texto da Lei, tais como o total para a despesa do Legislativo, para a despesa com pessoal geral e limites da dívida pública e das ações associadas à recondução desses limites. A LRF 5 também pode ser associada à CF3 por ter a preocupação com a dívida pública. Melo, Monteiro e Fadul (2007, p. 173) constataram "que os critérios técnicos instituídos pela LRF para estimar receitas e limitar despesas favoreceram ao maior equilíbrio orçamentário na gestão pública municipal".

A LRF6 apresenta o cuidado que o SCI deve ter com a correta aplicação do recurso público, mas foi apresentado separadamente na lei de forma a destacar que o recurso obtido com a alienação só pode ser destinado à realização de despesas de capital e pode ser associado ao NBC6, principalmente no que diz respeito a malversações e desvios de recursos, mas também pode ser aplicado ao conjunto da LRF que trata da gestão fiscal responsável e ainda se alinha com o disposto pelo INTOSAI (2004) conforme objetivo (INS4). Azevedo, Ensslin e Reina (2010, p. 38) asseveram, nesse sentido, ao afirmar que "Bons sistemas de Controle Interno previnem contra a fraude e minimizam os riscos de erros e irregularidades, e sua eficiência permite detectar essas irregularidades de atos intencionais ou não".

Outros autores apresentam uma lista de objetivos para o SCI, vinculados não só às atividades do setor público, mas a todas as organizações que também podem ser aplicados a realidade dos entes públicos. O Quadro 2 apresenta uma associação entre os objetivos do SCI nos setores público e privado. 
Quadro 2 - Vinculação de objetivos do SCI entre o setor público e o privado

\begin{tabular}{|c|c|c|c|c|}
\hline \multirow{2}{*}{$\begin{array}{l}\text { Objetivos no setor privado } \\
\text { Autores Referência }\end{array}$} & \multicolumn{4}{|c|}{ Objetivos no setor público } \\
\hline & $\begin{array}{c}\text { Constituição } \\
\text { Federal }\end{array}$ & LRF & $\begin{array}{c}\text { NBC T } \\
16.8\end{array}$ & INTOSAI \\
\hline $\begin{array}{l}\text { Proteção de ativos (salvaguardar o } \\
\text { patrimônio): Mattos e Mariano (2009); Pereira } \\
\text { (2009); Silva, Perez Junior e Oliveira (2002) }\end{array}$ & CF2 & LRF6 & $\begin{array}{l}\text { NBC1 } \\
\text { NBC } 6\end{array}$ & INS4 \\
\hline $\begin{array}{l}\text { Obtenção de informações apropriadas } \\
\text { (confiáveis e tempestivas): Mattos e Mariano } \\
\text { (2009); Pereira (2009); Silva, Perez Junior e } \\
\text { Oliveira (2002) }\end{array}$ & $--\mathrm{x-}$ & $--\mathrm{x-}$ & NBC3 & $--\mathrm{x}--$ \\
\hline $\begin{array}{l}\text { Apoiar a eficiência operacional (localização de } \\
\text { erros e desperdícios): Mattos e Mariano } \\
\text { (2009); Silva, Perez Junior e Oliveira (2002) }\end{array}$ & CF2 & --X-- & NBC5 & INS1 \\
\hline $\begin{array}{l}\text { Potencialização do êxito do processo } \\
\text { decisório: Pereira (2009); }\end{array}$ & $--\mathrm{X}--$ & --X-- & $\mathrm{NBC} 3$ & $--\mathrm{X}-$ \\
\hline $\begin{array}{l}\text { Induzir o comportamento focado no resultado: } \\
\text { Pereira (2009) }\end{array}$ & CF1 & LRF1 & NBC5 & INS1 \\
\hline $\begin{array}{l}\text { Garantir o respeito a normas e regulamentos da } \\
\text { entidade (comportamento ético): Pereira } \\
\text { (2009) } \\
\text { Silva, Perez Junior e Oliveira (2002) }\end{array}$ & $--\mathrm{X}--$ & $\begin{array}{l}\text { LRF } 3 \\
\text { LRF } 4 \\
\text { LRF } 5\end{array}$ & NBC4 & INS3 \\
\hline $\begin{array}{l}\text { Comprovar a veracidade de informações } \\
\text { contábeis e financeiras e operacionais: Silva, } \\
\text { Perez Junior e Oliveira (2002) }\end{array}$ & CF2 & $--\mathrm{X}--$ & NBC2 & --X-- \\
\hline
\end{tabular}

Fonte: Dados da pesquisa.

Os objetivos listado no Quadro 2 foram selecionados nos trabalhos de Silva, Perez Junior e Oliveira (2002); Mattos e Mariano (2009); e Pereira (2009). Percebe-se que estão inseridos no contexto de objetivos macro, tais como prevenir erros e fraudes que fazem parte de objetivos como proteção de ativos (fraudes) e potencializar a eficiência operacional (erros), e ambos, tanto fraude como erro, estão vinculados ao objetivo de comprovar a veracidade das informações contábeis, financeiras e operacionais. Nota-se maior aproximação entre os objetivos apresentados na literatura para o setor privado e os trazidos pela NBC T 16.8, o que dá conta de uma finalidade mais contábil do SCI, ou seja, de ser um sistema de apoio à contabilidade. Agrupados por tratarem de temas semelhantes, todos os objetivos apresentados neste estudo chega-se a uma lista sintetizada de onze objetivos do SCI no setor público: (1) Proteção de ativos; (2) Obtenção de informações apropriadas; (3) Apoio à efíciência operacional; (4) Potencialização do êxito do processo decisório; (5) Indução do comportamento focado no resultado; (6) Garantia do respeito a normas e regulamentos da entidade (comportamento ético); (7) Comprovação da veracidade de informações contábeis e financeiras e operacionais; (8) Exercício do controle das operações de crédito, avais e garantias, bem como dos direitos e haveres dos órgãos públicos; (9) Apoio ao controle externo no exercício de sua missão institucional; (10) Apoio e controle da responsabilidade na gestão fiscal, conforme a LRF; e (11) Zelo pelo cumprimento das obrigações e prestação de contas. Alguns desses objetivos, como já explorado, estão presentes na NBC T 16.8 que será comentada na seção seguinte em razão de sua aplicabilidade exclusiva ao setor público.

\subsection{A NBC T 16.8 do controle interno}


O SCI deve estar presente em toda a administração pública brasileira, apoiando as atividades de controle externo e sua atividade foi regulada em 2008 por normativo especifico sobre o SCI, a NBC T 16.8, que faz parte de um conjunto de outras onze normas que tratam da contabilidade aplicada ao setor público. A criação dessa norma está alinhada ao processo de convergência com as normas internacionais de contabilidade e também com um movimento de normatização de SCI e gestão de risco, tal como outras diretrizes e regulamentos que se destacam em diversos países Vinanni e Skaenvaek (2014) e Wood (2009). Dentre esses países destacam-se EUA, Reino Unido e União Europeia e regulamentos como o Código Cadbury (Comitê sobre os aspectos financeiros de Governança Corporativa, 1992); os Critérios de quadro de controle, (Canadian Institute of Chartered Accountants, 1995); as recomendações Turnbull (ICAEW, 1999; Financial Reporting Council, 2005); COSO e COSO-ERM (Comitê de Organizações Patrocinadoras da Comissão Treadway, 1992, 2004); a legislação Sarbanes-Oxley de 2002; e, a diretiva da UE sobre Fiscalidade (Parlamento Europeu e Conselho da União Europeia, 2006) (VINANNI; SKAENVAEK, 2014).

A norma brasileira está dividida em abrangência, estrutura e componentes. O normativo destaca a relevância do SCI ao considerar que ele deve ser exercido em todos os níveis das entidades do setor. Apresenta três categorias de SCI: (a) operacional, relacionado às ações que propiciam o alcance dos objetivos da entidade; (b) contábil, relacionado à veracidade e à fidedignidade dos registros e das demonstrações contábeis; e (c) normativo, relacionado à observância da regulamentação pertinente (CRC, 2008).

Outro aspecto relevante da norma é estruturar o SCI em principais elementos como ambiente de controle; mapeamento e avaliação de riscos; procedimentos de controle; informação e comunicação; e monitoramento que são apresentados de forma detalhada no Quadro 3.

\section{Quadro 3 - Estrutura e componentes do SCI}

\begin{tabular}{|l|l|}
\hline \multicolumn{1}{|c|}{ Componente } & \multicolumn{1}{c|}{ Definição } \\
\hline $\begin{array}{l}\text { Ambiente de } \\
\text { controle }\end{array}$ & $\begin{array}{l}\text { Deve demonstrar o grau de comprometimento em todos os níveis da administração com a } \\
\text { qualidade do controle interno em seu conjunto. }\end{array}$ \\
\hline $\begin{array}{l}\text { Mapeamento } \\
\text { de risco }\end{array}$ & $\begin{array}{l}\text { É a identificação dos eventos ou das condições que podem afetar a qualidade da } \\
\text { informação contábil. }\end{array}$ \\
\hline $\begin{array}{l}\text { Avaliação de de } \\
\text { risco }\end{array}$ & $\begin{array}{l}\text { Corresponde à análise da relevância dos riscos identificados, incluindo: (a) a avaliação da } \\
\text { probabilidade de sua ocorrência; (b) a forma como serão gerenciados; (c) a definição das } \\
\text { ações a serem implementadas para prevenir a sua ocorrência ou minimizar seu potencial; e } \\
\text { (d) a resposta ao risco, indicando a decisão gerencial para mitigar os riscos, a partir de } \\
\text { uma abordagem geral e estratégica, considerando as hipóteses de eliminação, redução, } \\
\text { aceitação ou compartilhamento. }\end{array}$ \\
\hline $\begin{array}{l}\text { Procedimento } \\
\text { de controle }\end{array}$ & $\begin{array}{l}\text { São medidas e ações estabelecidas para prevenir ou detectar os riscos inerentes ou } \\
\text { potenciais à tempestividade, à fidedignidade e à precisão da informação contábil, } \\
\text { classificando-se em: (a) procedimentos de prevenção - medidas que antecedem o } \\
\text { processamento de um ato ou um fato, para prevenir a ocorrência de omissões, } \\
\text { inadequações e intempestividade da informação contábil; (b) procedimentos de detecção - } \\
\text { medidas que visem à identificação, concomitante ou a posteriori, de erros, omissões, } \\
\text { inadequações e intempestividade da informação contábil. }\end{array}$ \\
\hline $\begin{array}{l}\text { Informação e e } \\
\text { comunicação }\end{array}$ & $\begin{array}{l}\text { Deve identificar, armazenar e comunicar toda informação relevante, na forma e no } \\
\text { período determinados, a fim de permitir a realização dos procedimentos estabelecidos e } \\
\text { outras responsabilidades, orientar a tomada de decisão, permitir o monitoramento de ações } \\
\text { e contribuir para a realização de todos os objetivos de controle interno. }\end{array}$ \\
\hline
\end{tabular}


Análise do sistema de controle interno no Brasil: objetivos, importância e barreiras para sua implantação

Monitoramento Compreende o acompanhamento dos pressupostos do controle interno, visando assegurar a sua adequação aos objetivos, ao ambiente, aos recursos e aos riscos.

Fonte: Elaborado pelo autor, com base em CRC (2008).

A estrutura apresentada pela norma difere em dois pontos da estrutura do COSO (2013): primeiro, a estrutura COSO reporta-se atualmente a cinco componentes, enquanto a norma lista seis, incluindo para além da avaliação do risco o mapeamento do riso; segundo, a diferença seria somente de nomenclatura, pois a norma considera procedimento de controle aquilo que o COSO determina como atividade de controle. Portanto, percebe-se que a norma tem como estrutura fundamental o estabelecido pelo COSO. Destaca-se que o COSO tem outra publicação intitulada Gerenciamento de Riscos Corporativos Estrutura Integrais (Enterprise Risk Management - Integrated Framework - Estrutura ERM) que difere desta estrutura aqui referenciada. Nessa publicação, o COSO ERM, como ficou conhecido, tem o foco na gestão do risco e possui as seguintes dimensões: ambiente de controle, fixação de objetivos, identificação de eventos, avaliação de riscos, atividades de controle, informação e comunicação e monitoramento.

\subsection{Estudos empíricos sobre o SCI}

Neste tópico, serão apresentados os estudos de Cabral e Ribeiro (2009) e de Sarens, Vissher e Van Gils (2010) que abordam aspectos relacionados a falhas no SCI do setor público no Brasil e sobre as práticas de controle interno no setor público da Bélgica, respectivamente. Esses estudos foram selecionados por apresentarem constatações relevantes sobre irregularidades em relação à LRF e às finalidades do SCI e sua relação com a gestão do risco.

Cabral e Ribeiro (2009) identificaram as principais irregularidades da LRF em municípios da região norte do Mato Grosso pelo Tribunal de Contas Estadual - TCE, são elas: (1) não realização de audiência pública e apresentação de deficit na execução orçamentária; (2) ausências dos instrumentos de transparência da gestão físcal; (3) constatação de fatos contábeis registrados indevidamente ou não contabilizados; (4) não efetiva cobrança e arrecadação dos tributos de competência constitucional do município; (5) ausência da transparência de contas públicas e não adoção de providências para constituição e arrecadação do crédito tributário; (6) ausência dos demonstrativos e impropriedades na análise do processo da Lei Orçamentária Anual; e (7) ausência de comprovação de que a reserva de contingência foi utilizada para cobrir passivos contingentes e outros riscos fiscais. Esse conjunto de irregularidades poderia ter sido evitado por um sistema de controle interno eficiente. $\mathrm{O}$ Quadro 4 apresenta um comparativo entre a irregularidade identificada e o componente e a falha no SCI.

Quadro 4 - Comparação entre irregularidade da LRF e falha no SCI

\begin{tabular}{|c|l|}
\hline Irregularidade & \multicolumn{1}{|c|}{ Componente e falha } \\
\hline (1) Não realização de & Componente: Monitoramento e Comunicação e Monitoramento do \\
audiência pública e & Risco \\
apresentação de déficit na & Falha: Falta de comunicação entre os setores para realização da \\
execução orçamentária & $\begin{array}{l}\text { audiência pública e inexistência de controle orçamentário regular e } \\
\text { tempestivo, não prevendo o risco de não cumprir a expectativa } \\
\text { orçamentária. }\end{array}$ \\
\hline (2) Ausências dos & Componente: Ambiente de Controle \\
\hline
\end{tabular}




\begin{tabular}{|c|c|}
\hline $\begin{array}{l}\text { instrumentos de transparência } \\
\text { da gestão fiscal }\end{array}$ & $\begin{array}{l}\text { Falha: Os gestores não desenvolverem uma estrutura de fomento da } \\
\text { transparência pública. }\end{array}$ \\
\hline $\begin{array}{l}\text { (3) Constatação de fatos } \\
\text { contábeis registrados } \\
\text { indevidamente ou não } \\
\text { contabilizados }\end{array}$ & $\begin{array}{l}\text { Componente: Atividades de Controle } \\
\text { Falha: Não realização de conciliações e conferências contábeis com } \\
\text { regularidade necessária e tempestiva, promovendo a exatidão dos dados } \\
\text { contábeis. }\end{array}$ \\
\hline $\begin{array}{l}\text { (4) Não efetiva cobrança e } \\
\text { arrecadação dos tributos de } \\
\text { competência constitucional do } \\
\text { município }\end{array}$ & $\begin{array}{l}\text { Componente: Ambiente de Controle e Monitoramento } \\
\text { Falha: O gestor deve exigir que os impostos sejam cobrados, por meio } \\
\text { dos setores específicos, criando mecanismo para este monitoramento. }\end{array}$ \\
\hline $\begin{array}{l}\text { (5) Ausências da transparência } \\
\text { de contas públicas e não } \\
\text { adoção de providências para } \\
\text { constituição e arrecadação do } \\
\text { crédito tributário }\end{array}$ & $\begin{array}{l}\text { Componente: Ambiente de Controle e Atividades de Controle } \\
\text { Falha: Os gestores não desenvolverem uma estrutura de fomento da } \\
\text { transparência pública e a efetividade na cobrança dos impostos. }\end{array}$ \\
\hline $\begin{array}{c}\text { (6)Ausência dos } \\
\text { demonstrativos e } \\
\text { impropriedades na análise do } \\
\text { processo da Lei Orçamentária } \\
\text { Anual (LOA) }\end{array}$ & $\begin{array}{l}\text { Componente: Mapeamento do Risco, Procedimentos de Controle e } \\
\text { Ambiente de Controle } \\
\text { Falha: Deve-se divulgar os demonstrativos constantes na lei e zelar pelo } \\
\text { seu atendimento dando ampla publicidade, criando mecanismos que } \\
\text { acompanham e divulguem a execução orçamentária. }\end{array}$ \\
\hline $\begin{array}{l}\text { (7) Ausência de comprovação } \\
\text { de que a reserva de } \\
\text { contingência foi utilizada para } \\
\text { cobrir passivos contingentes e } \\
\text { outros riscos fiscais }\end{array}$ & $\begin{array}{l}\text { Componente: Atividades de Controle e Monitoramento } \\
\text { Falha: Não foram feitos os registros contábeis que esclareçam em a } \\
\text { reserva de contingência foi utilizada, assim não existiam atividades e } \\
\text { monitoramento e controle que evitassem essa ausência. }\end{array}$ \\
\hline
\end{tabular}

Fonte: Elaborado pelo autor.

Esse comparativo (Quadro 4) permite identificar em que dimensão o controle interno não foi atendido e qual falha está subjacente ao processo de SCI da entidade.

Sarens, Vissher e Van Gils (2010) realizaram uma investigação sobre a gestão de riscos e práticas de SCI no setor de Segurança Social Pública - SSPI da Bélgica no qual avaliam em que medida as práticas atuais estão alinhadas com quadros internacionais de controle interno em relação à gestão e ao risco ERM e o INTOSAI. O estudo tinha duas questões de partida: (1) Em que medida as instituições públicas de segurança social belga desenvolvem a gestão de riscos e práticas de controle interno?; e (2) Até que ponto a gestão de riscos atual e práticas de controle interno nas instituições públicas de segurança social belga estão em linha com as melhores práticas, como estipulado por estruturas internacionais (ERM, INTOSAI)?

$\mathrm{Na}$ busca de responder essas questões, aplicaram um questionário para as SSPI belgas. As principais conclusões que obtiveram foram estas: (1) a gestão de riscos e controle interno não são altamente desenvolvidos dentro SSPI da Bélgica; (2) tanto a gestão de riscos e o controle interno são considerados para análise da viabilidade de projetos; (3) não estão integrados no contexto da organização de uma forma geral; e (4) são integrados de forma limitada no processo de planejamento estratégico e operacional, bem como para o funcionamento do dia a dia da organização.

Os autores concluem que ainda há um longo caminho para a SSPI belga implementar a filosofia de gestão de riscos em toda a entidade (incluindo o controle interno). Além disso, verificou-se que, quanto maior a SSPI é em termos de número de funcionários, mais a gestão de risco e o controle interno são integrados dentro da organização. Identificaram também que, nas pequenas organizações de SSPI, faltam pessoas que se dediquem à implementação e

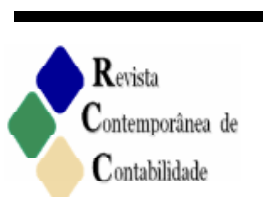


integração da gestão de riscos e do controle interno. Os resultados ainda sugerem que aqueles que têm a gestão do risco e o controle interno implantados não compreendem claramente como isso pode apoiá-los no processo de gestão da organização. Por fim, apontam que o controle interno, nessas organizações, é mais desenvolvido do que a gestão do risco, pois o principal objetivo do SCI é o de dar conformidade às leis e aos regulamentos.

\section{Metodologia Do Estudo}

Este estudo tem como objetivo realizar uma análise dos objetivos e da importância do controle interno no setor público e identificar barreiras para sua implantação. Para tal fez uso da pesquisa bibliográfica e documental. Essa pesquisa foi desenvolvida seguindo a classificação de Raupp e Beuren (2003), referente às tipologias de pesquisa aplicada à contabilidade que as divide em (1) quanto aos objetivos, (2) quanto aos procedimentos de pesquisa e (3) quanto à abordagem do problema.

A pesquisa, quanto aos seus objetivos, é exploratória. Esse posicionamento se justifica em razão dos poucos estudos sobre a relevância dos controles internos no contexto do setor público brasileiro. Em que pese ter-se estudos relevantes sobre o tema em instituições privadas no setor público, não se identificam estudos específicos que abordem seus objetivos, sua importância e suas barreiras. Com exceção do estudo de José Filho (2008), que tratou somente da importância do SCI na gestão pública, como referido no estudo (p. 98), o autor limitou-se "tão somente apresentar uma análise e uma maior reflexão e discussão com base na literatura pertinente sobre a importância do Controle Interno na Administração Pública [...]" e foi realizado antes da edição da NBC T 16.8., carecendo assim o tema de estudos mais robustos, com uma visão mais atual e aprofundada. Conforme Raupp e Beuren (2003, p. 81), " explorar um assunto significa reunir conhecimento e incorporar características inéditas, bem como buscar novas dimensões até então não conhecidas".

Quanto aos procedimentos, trata-se de uma pesquisa bibliográfica e documental. Raupp e Beuren (2003, p. 83) destacam que "Os procedimentos de pesquisa dizem respeito a como se conduz o estudo e, portanto, se obtém os dados". Esse procedimento de pesquisa foi escolhido para permitir evidenciar, por meio de resultados obtidos em pesquisas anteriores sobre o SCI, elementos relacionados aos objetivos, à importância e às barreiras para implantação. Complementarmente, realiza-se uma pesquisa documental em fontes primárias que apoiem atingir o objetivo do estudo.

A pesquisa bibliográfica foi realizada e organizada por meio de uma revisão sistemática da literatura, seguindo os passos apresentados por Saur (2011) que são: (1) a definição e enquadramento dos objetivos da revisão da literatura; (2) mapeamento da área estudada; e (3) síntese e apresentação dos resultados. Esses passos foram adaptados para este estudo da seguinte maneira: 1) organização de uma ficha de pesquisa: que permitiu criar um roteiro, identificando os passos realizados, as bases de dados consultadas, as justificativa para a escolha, as palavras-chave utilizadas, o período de pesquisa, os filtros criados, permitindo que o processo de pesquisa seja repetido por outros pesquisadores ou coautores para validar o nível de informação encontrada; 2) pesquisa em base de dados: inserir os critérios e filtros definidos na ficha de pesquisa nas bases de dados definidas; 3) selecionar os artigos: transportar os resumos, o autor e as informações de referência para o sistema Endnote $\circledR$, realizando a leitura dos resumos em arquivo Word $\AA$, apontando os artigos selecionados e 
verificando sua disponibilidade integral; e 4) download do artigos: verificar a disponibilidade da versão integral dos artigos por meio do acesso identificado como usuário aluno da universidade do Minho e Aveiro (Portugal) nas bases de dados e em portais de pesquisa por meio do Google Scholar ${ }^{\circledR}$.

Complementarmente a pesquisa bibliográfica, realizou-se uma pesquisa documental. Essa escolha está alicerçada no que destaca Raupp e Beuren (2003, p. 89) ao afirmar sobre a pesquisa documental que "Sua notabilidade é justificada no momento em que se podem organizar informações que se encontram dispersas, conferindo-lhes nova importância como fonte de consulta". A pesquisa documental realizada foi iniciada no portal do TCU do Brasil e da CGU em busca de relatórios que permitissem analisar os seus principais apontamentos. $\mathrm{O}$ objetivos dessa análise não é questionar a metodologia ou a forma de abordagem das constatações dos órgãos de controle, e sim buscar elementos nessa composição de inconsistências relatadas que reforcem a análise da importância do SCI no contexto público. Dessa forma, buscou-se, neste estudo, realizar a triangulação dos dados, que é a aplicação combinada de metodologias e fontes de dados, pesquisadores e teorias (DENZIN, 1970). Segundo Mozzato e Grzyboski (2011, p. 742), "A triangulação tem sido amplamente discutida e muito bem aceita, tanto na coleta como na análise de dados". A triangulação realizada é apresentada na Figura 2.

Figura 2 - Esquema de triangulação de dados primários

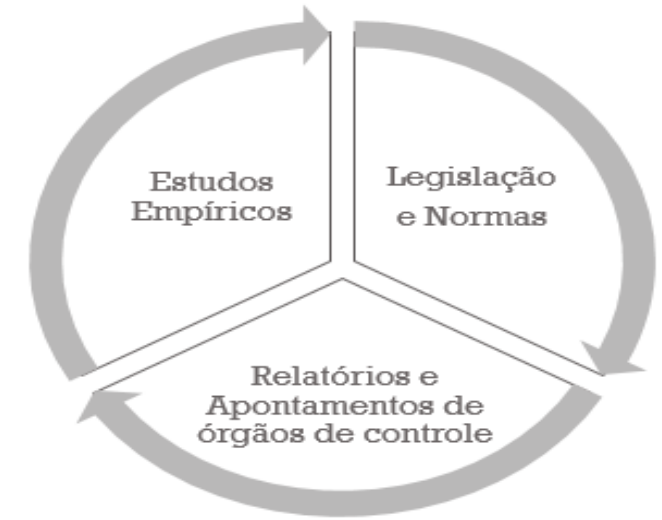

Fonte: Elaborada pelo autor.

Dessa forma, além do levantamento teórico realizado, focando estudos empíricos por meio da revisão sistemática da literatura, para atingir os objetivos do estudo, buscaram-se normas e regulamentos existentes que tratassem do funcionamento, dos objetivos e da importância do SCI, bem como relatórios e apontamentos do TCU e da CGU sobre o tema, realizando uma triangulação das informações para construção da análise do estudo, apoiado no entendimento de Godoy (2010) ao afirmar que a triangulação é um critério de credibilidade da pesquisa qualitativa.

Quanto à abordagem do problema, esta pesquisa está classificada como qualitativa. Esse enquadramento parte do pressuposto de que as entidades são organizações sociais que possuem problemas de controle e gestão. A abordagem qualitativa de um problema de pesquisa que permite conhecer a natureza de um fenômeno social, de forma mais profunda Raupp e Beuren (2003). Tendo em vista os objetivos do estudo, a abordagem qualitativa do problema permite tratá-lo com a profundidade necessária. 


\subsection{Descrição da Revisão Sistemática da Literatura}

Inicialmente, realizou-se uma pesquisa na base de dados SCOPUS, utilizando os termos "Internal Control", "and" e "Public Setor" como palavras-chave, somente em ciências sociais e humanas e em artigos, com a opção de todos os anos, conforme Figura 3, extraída do site de busca, após os resultados, identificando o histórico da pesquisa.

Figura 3 - Critérios e Resultados da Pesquisa na SCOPUS

\begin{tabular}{lrr}
\hline Search history & Combine queries... & e.g. \#1 AND NOT \#3. \\
\hline 1 (KEY(internal control) AND KEY(public sector)) AND DOCTYPE(ar) AND SUBJAREA(mult OR arts OR busi & 5 document results \\
OR deci OR econ OR psyc OR soci) & \\
\hline
\end{tabular}

Fonte: Dados da pesquisa.

Como evidenciado na Figura 3, essa consulta resultou em cinco artigos. Após a leitura dos resumos, dois deles foram excluídos da amostra por não terem relação ao tema: Crafting $a$ strategy for improved communal waste management in mafikeng, de Kadama (2013), e Relationship between job strain and smoking cessation: the Finnish Public Sector Study, de Kouvonen et al. (2009). Também foi excluído o estudo de Boullanger (2013), L'audit interne dans le secteur public, por ser da revista francesa Revue française d'administration publique que não estava disponível para acesso pela rede da Universidade do Minho e Aveiro.

Tendo em vista o baixo número de artigos localizados, fez-se o mesmo procedimento na base de dados Multidisciplinar Currente Contents Connect, porém buscando as expressões "internal control" e "public setor" em tópicos, pois essa base não permite a pesquisa por palavras-chave. O primeiro resultado obtido evidenciou um total de 84 resultados. Para seu filtro, foram selecionados somente artigos em língua inglesa, em razão de ser a segunda língua de domínio do autor e das áreas que se aproximam do controle interno no foco do estudo, como evidenciado na Figura 4, gerando 50 resultados.

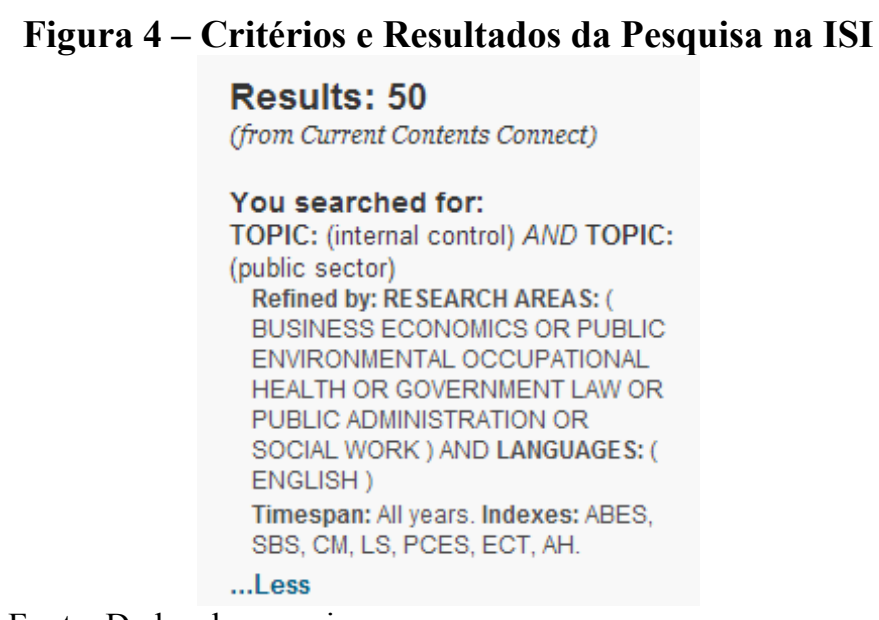

Fonte: Dados da pesquisa.

Um dos resultados - The uncertainties of risk management A field study on risk management internal audit practices in a Finnish municipality - se repetiu. Após a leitura dos resumos, 33 estudos foram excluídos por não terem referência direta com o SCI no setor 
público, sendo que 17 passaram por uma segunda análise para verificar possíveis contribuições ao estudo.

Procedimento de pesquisa semelhante fez-se na Base B-on (Biblioteca online de conhecimento), selecionando-se no assunto a expressão exata "internal control" e "public sector", somente artigos em língua inglesa, gerando quatro resultados, sendo que o artigo Management trade-offs of internal control and external auditor expertise se repetiu na pesquisa e não estava disponível para acesso e um dos resultados não se tratava de um artigo publicado em periódico: In Brief (Public Company Accounting Oversight Board's Auditing Standard No. 5)(Smart Business Advisory and Consulting LLC got finance from Great Hill Partners L.L.C.) também não disponível para acesso. Posteriormente, repetiu-se a pesquisa na B-on utilizando somente a expressão "internal control", com uma seleção de subáreas conforme Figura 5, gerando um total de 50 resultados. Após a leitura dos resumos, somente seis estudos foram selecionados para a leitura integral por se tratarem diretamente de SCI no setor público.

Figura 5 - Critérios e Resultados da Pesquisa na B-on

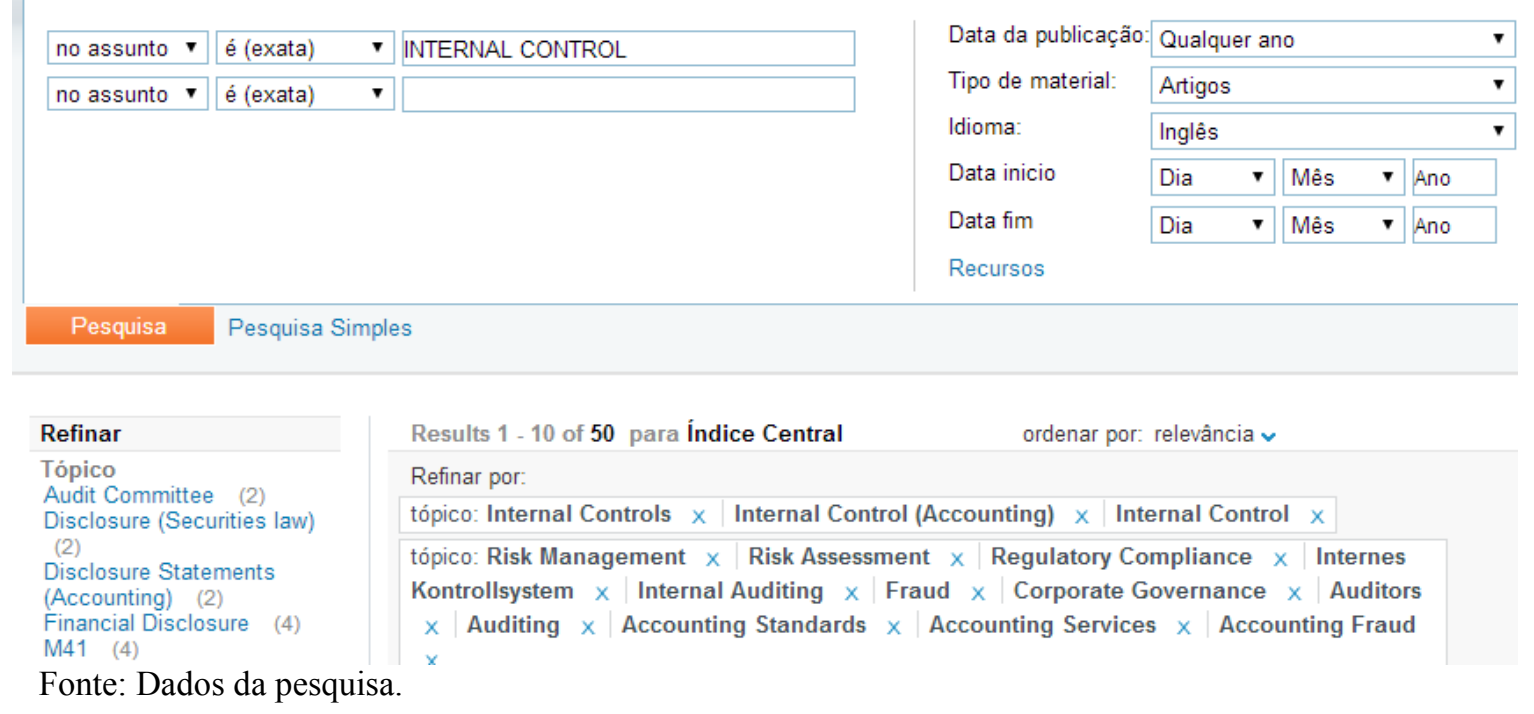

\section{Apresentação e Discussão dos Resultados}

\subsection{Resultado da Revisão Sistemática da Literatura}

A revisão sistemática da literatura permitiu identificar um conjunto de 25 estudos que poderiam subsidiar a definição da importância e das barreiras para a implantação do SCI no setor público. Após a leitura da integralidade dos estudos, foram selecionados dez estudos empíricos que apresentavam maior relevância ao tema em razão de abordar problemas de implantação e destacar a importância do SCI no setor público (Quadro 5).

Quadro 5 - Resultado da Revisão Sistemática da Literatura

\begin{tabular}{|l|c|}
\hline \multicolumn{1}{|c|}{ Título } & Autor / ano \\
\hline $\begin{array}{l}\text { The uncertainties of risk Management a field study on risk management } \\
\text { internal audit practices in a Finnish municipality }\end{array}$ & Vinnari e Skaerbaek \\
\hline
\end{tabular}


Análise do sistema de controle interno no Brasil: objetivos, importância e barreiras para sua implantação

\begin{tabular}{|l|c|}
\hline Improving the internal control system within universities & Popescu e Dascalu (2012) \\
\hline $\begin{array}{l}\text { Internal Control Systems: Effectiveness of Internal Audit in Risk } \\
\text { Management at Public Sector Enterprises }\end{array}$ & $\begin{array}{c}\text { Vijayakumar e Nagaraja } \\
\text { (2012). }\end{array}$ \\
\hline $\begin{array}{l}\text { Court of auditors - the assessment of internal controle system in the public } \\
\text { sector in Romania case stuy bihor country }\end{array}$ & $\begin{array}{c}\text { Simona e Gheorghe } \\
(2012)\end{array}$ \\
\hline $\begin{array}{l}\text { Impact of Public Internal Financial Control on Public Administration in } \\
\text { Croatia }\end{array}$ & $\begin{array}{c}\text { Dragija,Hladika e Vasicek } \\
\text { (2010) }\end{array}$ \\
\hline $\begin{array}{l}\text { The Causes and Consequences of Internal Control Problems in Nonprofit } \\
\text { Organizations }\end{array}$ & $\begin{array}{c}\text { Petrovits, Shakespeares e } \\
\text { Shih (2010) }\end{array}$ \\
\hline $\begin{array}{l}\text { A contingency theory perspective on the risk management control system } \\
\text { within Birmingham City Council }\end{array}$ & Wood (2009) \\
\hline $\begin{array}{l}\text { Risk management in public sector research: approach and lessons learned at } \\
\text { a national research organization. }\end{array}$ & Leung e Isaacs (2008) \\
\hline Risk management: developing a framework for a water authority & Dalgleish e Cooper (2005) \\
\hline $\begin{array}{l}\text { How did enterprise risk management first appear in the Korean public } \\
\text { sector? }\end{array}$ & Kim (2004) \\
\hline
\end{tabular}

Fonte: Dados da pesquisa.

O estudo de Vinnari e Skaerbaek (2014) teve por objetivo analisar a implementação da gestão de riscos. Os autores estudaram as soluções de gestão de risco, como foi o surgimento, de quem foram as responsabilidades, quais tecnologias significativas foram utilizadas em um município da Finlândia, evidenciado que o responsável pela gestão de risco dentro do município foi em grande parte a Unidade de Auditoria Interna (IAU), que entrou em ação quando eventos inesperados ocorreram e propôs soluções de gerenciamento de risco.

O sistema de controle interno nas universidades da Romênia foi o tema central do estudo de Popescu e Dascalu (2012). Objetivaram evidenciar melhorias nos sistemas de controle interno das universidades. Foi fundamentado em dados de literatura sobre estado de implementação do controle interno nas universidades públicas e analisou os requisitos da legislação nacional sobre os sistemas de controle interno.

Vijayakumar e Nagaraja (2012) fizeram uma análise à luz da eficácia e da eficiência da auditoria interna tratando-a como uma ferramenta do SCI avaliando seu impacto na gestão do risco e nas práticas de auditoria de empresas públicas. Concluiram que um forte sistema de auditoria interna é vantajoso para a gestão do risco e na prevenção e deteção de erros e fraudes.

Simona e Gheorghe (2012) realizaram estudo com o objetivo de responder a duas questões: (1) Qual é o nível e o estado atual do sistema de controle interno no sistema romeno?; e (2) Entendemos e respeitamos a noção de controle interno das finanças públicas? Os autores identificaram que as auditorias são formais e não são orientadas para a necessidade da gerências, não produzem efeito na gestão eficiente. Concluem que, a fim de reduzir o risco de erros, se deve implementar procedimentos claros de controle interno para todas as atividades realizadas. Identificaram ainda que o sistema atual não atende à Lei n. 119/1999, relativa ao acompanhamento e controle interno financeiro preventivo daquele país.

Dragija, Hladika e Vasicek (2010) descrevem as fases da implantação de Sistema de Controle Interno Financeiro no setor público (CIPF) da Croácia, mostrando o impacto que tem na Nova Gestão Pública e apresentam a abordagem na implementação de CIFP na Eslovénia e na Bósnia-Herzegovina.

Petrovits, Shakespeares e Shih (2010) analisaram as causas e consequências das deficiências de controle interno no setor sem fins lucrativos, utilizando uma amostra de 27.495 instituições de caridade pública de 1999 a 2007. Identificaram que informações sobre 
o controle interno pode afetar diretamente os financiadores dessas organizações e que a probabilidade de falhas de controle interno é mais recorrente nas menores organizações, nas em crescimento e nas que apresentam dificuldades financeiras.

Wood (2009) realizou um estudo de caso na Câmara Municipal de Birminghan, Inglaterra, sobre o sistema de controle interno e gerenciamento de risco que busca ampliar a teoria existente, desenvolvendo uma teoria de contingência para o setor público. Identifica que os controles estão contingenciados pelas variáveis da política do governo central, pela tecnologia da informação e comunicação e pelo porte da organização.

Leung e Isaacs (2008) descrevem o processo do principal órgão de pesquisa do Canadá, sendo uma entidade do setor público (National Reserch Council - NRC) em busca de um modelo adequado de gestão de risco que contemple seus projetos, programas e portfólio. Constatam que, apesar de avanços na gestão do NRC, ainda tem muito a progredir no seu processo de gestão do risco em uma unidade governamental de pesquisa, principalmente em como deve melhorar no gerenciamento dos riscos estratégicos e operacionais, desenvolver mecanismo e meios de partilhar informação e experiência pela organização, permitindo a tomada de decisão com apoio na informação sobre o risco de forma oportuna. Relatam que a cultura e a mentalidade de gestão do risco devem ser incorporadas a um grupo maior de pessoas dentro da organização.

Dalgleish e Cooper (2005) realizaram um estudo de caso das principais questões a serem abordadas na implementação de um sistema de gestão de risco, com base nas experiências de uma 'autoridade de água' na Austrália. Entre os principais achados do estudo, destaca-se que identificaram riscos estratégicos para o setor como a incapacidade de fornecer o serviço com um nível de segurança confiável e listaram os requisitos essenciais para uma abordagem integrada para a gestão dos riscos em uma 'autoridade da água'.

Kim (2004) analisou um modelo de gestão de crise, como Crisis Management Guideline of Public Organizations (CMGPO), aplicado ao sistema governamental de gestão de crise no setor público coreano. Os estudos foram coletados nas bases de dados indicadas na metodologia e a motivação para sua seleção foram estas: (1) sua relação com o SCI no setor público; (2) que fossem estudos empíricos; e (3) que apoiassem na construção de um referencial em termos de importância e barreiras do SCI no setor público.

Esses estudos foram de grande relevância para a construção dos tópicos 4.3 e 4.4 que tratam da importância do SCI e das barreiras para sua implantação no setor público.

\subsection{Da Pesquisa Documental}

A pesquisa documental foi realizada em dois relatórios. Primeiro, relativo à auditoria de 23 hospitais universitários federais brasileiros feito pelo TCU; e o segundo, na prestação de contas da Presidente da República, referente ao ano de 2012, uma vez que a de 2013 não estava disponível até o mês de março de 2014, época desta coleta de dados. A escolha desses dois documentos deu-se primeiro por seu conteúdo esclarecedor em relação ao tema, segundo por permitir identificar falhas no SCI apontadas por dois segmentos: um de controle externo, o TCU; e outro de controle interno, no caso a Secretaria Federal de Controle Interno, vinculada à Contadoria Geral da União.

Os principais resultados do relatório de auditoria do TCU em termos de falhas apontadas foram: a) falhas nas ferramentas de controle interno nas áreas de licitação e contratos; b) falta de capacitação de quem exerce funções de controle; c) falta de recursos 
humanos destinados as atividades de controle; d) falta de rotatividade dos funcionários e responsáveis por áreas; e e) falhas na execução das atividades de licitação e contratos. As conclusões apontam ainda que $57 \%$ dessas instituições de saúde têm capacitação de funcionários deficiente nas áreas de licitações e contratos, e $74 \%$ delas não monitoram as atividades e desempenho do setor, em $61 \%$ dos hospitais nem há definição clara das competências, atribuições e responsabilidades da área de licitações. Destacam ainda problemas relacionados à gestão da ética, pois constataram que $78 \%$ dos hospitais não realizam efetivamente. Do relatório extrai-se uma série de 37 inconformidades decorrentes de falhas no SCI que foram tratadas em uma planilha no Excel® ${ }^{\circledR}$ para ordenar pela maior ocorrência no período. Optou-se por apresentar na Tabela 1 somente as presentes em mais de $50 \%$ dos hospitais, totalizando assim 16 deficiências.

Tabela 1- Principais deficiências em hospitais universitários

\begin{tabular}{|l|c|c|}
\hline \multicolumn{1}{|c|}{ Deficiência } & Quantidade & \multicolumn{1}{c|}{$\%$} \\
\hline Ausência de controle das aquisições ocorridas & 22 & $91 \%$ \\
\hline Inexistência de código de ética próprio & 20 & $87 \%$ \\
\hline Inexistência ou deficiência na gestão de ética & 18 & $78 \%$ \\
\hline Inadequações na estrutura organizacional & 18 & $78 \%$ \\
\hline $\begin{array}{l}\text { Falta de monitoramento das atividades e do desempenho da área de licitações e } \\
\text { contratos }\end{array}$ & 17 & $74 \%$ \\
\hline Insuficiência de pessoal & 16 & $70 \%$ \\
\hline Inexistência de sistemática de revisão dos trabalhos & 16 & $70 \%$ \\
\hline Insuficiência de atuação na área de licitações e contratos & 15 & $65 \%$ \\
\hline $\begin{array}{l}\text { Ausência de orientação formal para rotatividade de responsáveis por atividades } \\
\text { críticas da entidade ** }\end{array}$ & 14 & $64 \%$ \\
\hline Ausência de normas ou manuais para a realização das principais atividades & 14 & $62 \%$ \\
\hline $\begin{array}{l}\text { Ausência de clareza sobre as competências, atribuições e responsabilidades de áreas } \\
\text { e cargos efetivos e comissionados }\end{array}$ & 14 & $61 \%$ \\
\hline Programa de capacitação insuficiente e inadequado & 13 & $57 \%$ \\
\hline Ausência de comunicação das responsabilidades & 15 & $57 \%$ \\
\hline Falta de divulgação e promoção da ética & 12 & $52 \%$ \\
\hline Falta de sistema de avaliação de desempenho de servidores (ou este é inadequado) & 12 & $52 \%$ \\
\hline Inexistência de aprovação parcial dos trabalhos & 12 & $52 \%$ \\
\hline
\end{tabular}

Fonte: Dados da pesquisa.

Os dados indicam que 16 das 37 deficiências estão presentes em mais de $52 \%$ dos hospitais. A deficiência mais presente é a ausência de controle das aquisições ocorridas, presente em $91 \%$ dos hospitais da amostra, e a inexistência do código de ética em $87 \%$, seguidas da inexistência ou deficiência na gestão da ética $78 \%$, e inadequações na estrutura organizacional $78 \%$. Na sequência, apresentam-se deficiências relacionadas às licitações ou ao setor de licitações. As deficiências que foram constatas em menor quantidade nos hospitais foram: não adoção do código de ética do setor público (4\%); normas ou manuais deficientes ou pouco detalhados (13\%); e ausência de análise de alterações contratuais também inobservância dos limites legais para composição de comissões, ambas com (14\%).

O relatório de prestação de contas anual da Presidência da República apresenta informações sobre o controle interno. No relatório, constam as falhas mais frequentes apontadas em 369 relatórios de projetos que foram objeto de auditoria interna de competência da Secretaria Federal de Controle Interno, órgão responsável pelo SCI do Governo Federal. Essas falhas estão apontadas na Tabela 2. 
Tabela 2 - Principais irregularidades constatadas pela CGU em projetos

\begin{tabular}{|l|c|}
\hline \multicolumn{1}{|c|}{ Tipo de irregularidade } & Quantidade \\
\hline Falha no processo de seleção e contratação de fornecedores & 88 \\
\hline Deficiência no controle de bens patrimoniais & 38 \\
\hline Falhas no processo de seleção e contratação de consultores & 36 \\
\hline Falhas na concessão de passagens aéreas e diárias & 35 \\
\hline Ausência e inadequação dos controles sobre a execução do projeto & 29 \\
\hline Falhas na execução e gerenciamento de contratos & 29 \\
\hline Baixa execução física e financeira do projeto & 17 \\
\hline Falhas em processos de liquidação e pagamento de fornecedores & 16 \\
\hline Falhas em processos de liquidação e pagamento de consultores & 11 \\
\hline Aquisição antieconômia, superfacturada ou gastos desnecessários & 9 \\
\hline Falhas na classificação orçamentária/contábil da despesa & 6 \\
\hline
\end{tabular}

Fonte: (CGU, 2013).

A irregularidade mais constatada está relacionada a processos liciatórios, semelhante ao apontado pelo TCU em seu relatório. Com base nessas irregularidades, a CGU apontou uma série de melhorias que deveriam ser implementadas no projetos, tais como (1) aprimoramento dos controles sobre a execução física/financeira dos projetos, focando o atingimento dos objetivos e metas finalísticos; (2) readequação no planejamento das aquisições, de sorte a propiciar garantia de que os bens e serviços contratados guardam conformidade com as condições de elegibilidade e são adequados às finalidades e méritos de cada projeto; (3) aprimoramento da sistemática de contratação de consultores, com reforço do acompanhamento sobre os produtos entregues, de modo a garantir que estejam conforme às necessidades identificadas; e (4) reforço no controle da concessão e prestação de contas de convênios.

\subsection{Da Importância Do Sci Para O Setor Público}

Para a identificação da importância do SCI no setor público, foi necessário inicialmente identificar quais são os objetivos do SCI no contexto público, também foi necessário fazer uma revisão da literatura e da NBCASP 16.8 e, por fim, buscar em relatórios do TCU e da CGU irregularidades para confrontar sua necessidade. No Quadro 6, é apresentada uma categorização da importância do SCI. Para essa categorização, dois critérios foram utilizados: ter vinculação a um ou mais dos objetivos apresentados na revisão da literatura e terem sido definidos, no mínimo, dois estudos apresentados no Quadro 5 fruto da revisão sistemática da literatura.

\begin{tabular}{|c|c|c|}
\hline \multicolumn{3}{|c|}{ Quadro 6 - Categorização da Importância do SCI no setor público } \\
\hline Categoria & Definição & Autores \\
\hline $\begin{array}{ll}\text { Gestão } & \text { do } \\
\text { Risco } & \end{array}$ & $\begin{array}{l}\text { Esta categoria é relacionada à relevância que } \\
\text { o SCI deve ter na gestão do risco, no seu } \\
\text { monitoramento e avaliação, ainda sua } \\
\text { importância para o alcance dos objetivos e } \\
\text { metas, evitar desperdícios, como forma de } \\
\text { aprimorar a gestão estratégia e até mesmo a } \\
\text { gestão de custos. }\end{array}$ & $\begin{array}{l}\text { Kim (2004); Roberts e Candreva } \\
\text { (2006); Dragija, Hladika, \& Vasicek, } \\
\text { (2010); Popescu e Dascalu, (2012); } \\
\text { Vijayakumar \& Nagaraja (2012); } \\
\text { Simona e Gheorghe (2012); Vinnari e } \\
\text { Skaerbaek (2014); Dalgleish e Cooper } \\
\text { (2005); Wood (2009); Leung e Isaacs } \\
(2009)\end{array}$ \\
\hline Informação & $\begin{array}{l}\text { Esta categoria relaciona-se à correção da } \\
\text { informação contábil, sua tempestividade e }\end{array}$ & $\begin{array}{l}\text { Vijayakumar e Nagaraja (2012); } \\
\text { Simona e Gheorghe }(2012)\end{array}$ \\
\hline
\end{tabular}


Análise do sistema de controle interno no Brasil: objetivos, importância e barreiras para sua implantação

\begin{tabular}{|c|c|c|}
\hline & $\begin{array}{l}\text { fidedignidade, como forma não só de apoiar } \\
\text { o processo decisório mas de proteger o } \\
\text { patrimônio, salvaguardá-lo, protegendo os } \\
\text { ativos }\end{array}$ & \\
\hline $\begin{array}{l}\text { Comporta- } \\
\text { mento ético }\end{array}$ & $\begin{array}{l}\text { Esta categoria vincula-se ao reforço à } \\
\text { implementação de um comportamento mais } \\
\text { ético, de respeito a normas e regulamentos } \\
\text { que o SCI deve estabelecer dentro das } \\
\text { organizações, evitando fraudes, desvios e } \\
\text { posturas antiéticas. }\end{array}$ & 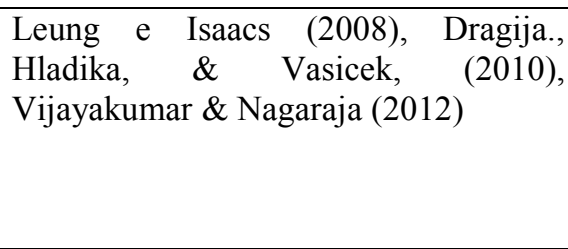 \\
\hline $\begin{array}{ll}\text { Imagem } & \text { da } \\
\text { Entidade } & \end{array}$ & $\begin{array}{l}\text { O SCI ajuda a organização a obter o apoio } \\
\text { da sociedades (doações), melhora a relação } \\
\text { com os órgãos de controle, melhora a } \\
\text { imagem do governo local com órgãos } \\
\text { financiadores, com a sociedade em geral e } \\
\text { evita danos a reputação. }\end{array}$ & $\begin{array}{l}\text { Campbell, Campbell e Adams (2006) } \\
\text { Petrovits, Shakespeare e Shih, (2011) } \\
\text { Vijayakumar \& Nagaraja (2012); } \\
\text { Simona e Gheorghe (2012) }\end{array}$ \\
\hline $\begin{array}{l}\text { Proteção dos } \\
\text { recursos } \\
\text { públicos }\end{array}$ & $\begin{array}{l}\text { Tem relação com a relevância do SCI para } \\
\text { apoiar a ação responsável, eficiente dos } \\
\text { gestores públicos, evitando fraudes, } \\
\text { malversação de recursos e desvios, ou } \\
\text { comprometimentos financeiros do setor. }\end{array}$ & $\begin{array}{l}\text { Dragija., Hladika, \& Vasicek, (2010); } \\
\text { Vijayakumar \& Nagaraja (2012); } \\
\text { Popescu e Dascalu (2012) }\end{array}$ \\
\hline
\end{tabular}

Fonte: Dados da pesquisa.

A maioria dos autores, como Dalgleish e Cooper (2005), Wood (2009), Simona e Gheorghe (2012) e Vinnari e Skaerbaek (2009), relaciona a questão da relevância do controle interno com a gestão do risco. Vinnari e Skaerbaek (2014, p. 496) que analisaram gestão de risco em um município finlandês identificaram que o controle interno e a gestão do risco podem apoiar no combate a fraudes. Para eles, "a ocorrência de fraude em uma organização pode ser considerada como o resultado de uma deficiência do sistema de gestão de riscos". Os autores sustentam que esse problema poderia ser evitado com as ferramentas de controle interno, tal como o quadro COSO. Assim, essa categoria alinha-se com os indicativos do COSO e com a estrutura indicada pela NBC T 16.8, apresentada no Quadro 3 que estabelece seis componentes do SCI, entre eles o mapeamento e a avaliação do risco. Os dados da pesquisa documental também apontam nesse sentido, pois um elevado número das irregularidades constatadas está identificada com a área de licitações que podem não ser somente erros formais, mas fraudes nos processos para benefícios de fornecedores e servidores públicos. Essa categoria (gestão do risco) pode ser associada aos objetivos como o apoio à eficiência operacional, potencializar o êxito do processo decisório e induzir o comportamento focado no resultado.

Autores como Leung e Issac (2008), Vijayakumar e Nagaraja (2012) e Simona e Gheorghe (2012) destacam a relevância do SCI para a organização da informação dentro das organizações, para a proteção de seus ativos e para a segurança da informação contábil. Sua instrumentalização como elemento de qualidade da informação que ajuda a gestão pode apoiar a transparência pública e o controle social. A falta de informação pode gerar problemas para a organização, não só dificultando o processo decisório, mas influenciar o não atendimento de aspectos da legais, como constatado no estudo de Cabral e Ribeiro (2009), explorado no Quadro 2, das falhas mais comuns - item 2 e 7. Também a Tabela 2 apresenta que a falta de informação (controle) sobre as aquisições ocorridas como a principal falha constatada nos hospitais públicos estudados. Leung e Isaacs (2008) defendem que o SCI dentro das organizações é visto como um instrumento de governança, auxiliando a gestão por 
meio de informações na tomada de decisões, qualificando a comunicação dentro da organização. Os dados do relatório da CGU, resumidos na Tabela 3, apontam ainda que existe ausência e inadequação dos controles sobre a execução do projeto e falhas na classificação contábil da despesa. A categoria informação associa-se aos seguintes objetivos do SCI: obtenção de informações apropriadas, comprovação da veracidade de informações contábeis e financeiras e operacionais, zelo pelo cumprimento das obrigações e prestação de contas, principalmente no que diz respeito a prestação de contas.

Para Dragija., Hladika e Vasicek, (2010) e Vijayakumar \& Nagaraja (2012), os controles internos têm papel fundamental no reforço de atitudes éticas. Como apresentado na Tabela 1, irregularidades relacionadas è ética foram a segunda e a terceira mais presentes nos hospitais da amostra e podem, portanto, ser comuns em estruturas do setor público. Assim, o reforço do comportamento ético é uma condicionante para a sua regularidade em termos de gestão como apontado pelo TCU. Jordão, Souza e Toledo (2012) destacam que a implementação de um modelo adequado de CI pode proporcionar uma melhoria nas práticas de gestão, qualificar o processo de gestão - tudo isso dentro de padrões éticos. Essa importância do SCI atende a um dos objetivos do SCI que é garantir o respeito a normas e regulamentos da entidade (comportamento ético)

Petrovits, Shakespeare e Shih (2010) estudaram o controle interno em instituições sem fins lucrativos e destacam que, se uma organização relata um problema de controle interno, os doadores podem optar por apoiar uma outra organização, que faça melhor utilização dos recursos doados, destacando a importância do controle interno para a manutenção da imagem da organização e para a ampliação e manutenção do nível de doadores. Para Campbell, Campbell e Adams (2006), a adoção de um modelo de CI pode ser capaz de gerar valor nas corporações que o adotam por colaborar para a condução das estratégias, a qualidade das informações internas e externas, o monitoramento dos riscos, a melhoria da prestação de contas, a adequação à legislação e, ainda, a redução de fraudes. Vijakamur e Nakajara (2012) concluem que um adequado SCI garante confiabilidade financeira nos relatórios, a conformidade com leis e regulamentos e evita danos da reputação. Essa categoria alinha-se principalmente a dois objetivos do SCI: primeiro, apoiar o controle externo no exercício de sua missão institucional, pois, se a organização tem um boa imagem em termos de implementação de SCI, terá o apoio e a segurança dos órgãos de controle de que seu funcionamento é adequado; segundo, apoiar e controlar a responsabilidade na gestão fiscal conforme a LRF. Se o órgão demonstra responsabilidade na sua gestão fiscal, reforça sua imagem de "saúde financeira" perante as demais esferas de governo, órgão de controle e entidades financiadoras como bancos. Uma das falhas apontadas pelo estudo de Cabral e Ribeiro (2009) estava relacionada à ausência de transparência que comprova a importância do SCI para a imagem da organização.

Marçola (2014, p. 84) conclui em seu estudo que "Os controles internos e externos estabelecidos no ordenamento jurídico nacional trouxeram bases claras para $\mathrm{o}$ agir 'politicamente responsável' e o 'administrativamente eficiente' do administrador público, que, combinados com a auditoria interna, possam finalmente levar o Estado a um refinamento e aprimoramento na gestão pública brasileira”. Para Jordão, Souza e Toledo (2012) mesmo que não exclua a probabilidade de ocorrência de erros totalmente, os controles internos podem colaborar para que esses sejam conhecidos, corrigidos e evitados. Essa proteção aos recursos públicos pode evitar que falhas como baixa execução física e financeira do projeto, aquisição antieconômia, superfacturada ou gastos desnecessários, falhas em processos de pagamentos 
identificados na Tabela 2 podem deixar de ocorrer. Essas falhas indicam que os objetivos do SCI, como a proteção de ativos, podem induzir o comportamento focado no resultado e exercer o controle das operações de crédito, avais e garantias, bem como dos direitos e haveres dos órgãos públicos não foram atendidos.

\subsection{Barreiras Para Implantação}

Dalgleish e Cooper (2005) apontam que um dos problemas da eficácia do SCI no setor público pode ser a falta da aplicação de um quadro mais rigoroso de controle, por exemplo para identificação de risco e de determinar um curso de ação, com base em decisões bem informadas, entendimento corroborado posteriormente por Marçola (2014). Criticam também a aversão do setor público ao gerenciamento do risco, uma falta de preocupação do setor em gerir os riscos que estão sujeitos, com uma preocupação maior com a prestação de contas. $\mathrm{O}$ destaque da importância da gestão do risco também foi referido por Azevedo, Ensslin e Reina (2010), porém Wood (2009) discorda ao destacar que algumas iniciativas do setor privado para melhorar seus sistemas de controle interno e de risco foram incorporadas ao setor público onde a gestão de risco é vista como uma dimensão importante que pode auxiliar o alcance dos objetivos estratégicos.

Para Farias, Luca e Machado (2010), o SCI é visto como um processo complexo que envolve vários elementos que devem interagir integralmente na busca dos objetivos, razão pela qual sua implementação depende e muito do fator humano. Leung e Isaacs (2008) identificaram que, nesse tipo de processo de mudança organizacional, se deve dedicar tempo para desenvolver práticas e incultar a cultura de atividades de gestão de risco e de controle interno nas pessoas, consideram como essencial estabelecer um programa de estratégia, comunicação e treinamento que envolva todos os funcionários da organização. Azevedo, Ensslin e Reina (2011), que estudaram o controle interno em uma Fundação pública, identificaram que a falta de elementos relacionados à gestão de pessoal, como plano de carreira, relatórios de desempenho, manuais internos, rotação de funcionários e segregação de funções, dificulta a aderência aos controles internos, gerando uma insegurança nos controles existentes. Para Mattos e Mariano (2009, p. 39), nenhum SCI terá sucesso se não considerar o fator humano com "seus problemas, tentações e falhas", destacam que o sucesso será obtido por aquele gestor que conseguir uma participação voluntária dos funcionários no seu SCI.

A falta de conhecimento técnico, informação e treinamento de funcionários é também apontada por Roberts e Candreva (2006) e Dragija, Hladika, e Vasicek, (2010). A falta de conhecimento pode ser associada a algo que Wood (2009) identificou. Para ele a eficácia de um sistema de controle interno não depende apenas da sua concepção geral, mas da maneira como os controle vão ser implantados. Para tal percebe-se que é preciso a participação das pessoas no processo e, para participarem de forma correta, é necessário algum conhecimento técnico, informação e treinamento.

Outro ponto identificado como motivador de dificuldades para o controle interno no setor público é o aumento dos custos operacionais e administrativos (PETROVITS; SHAKESPEARE; SHIH, 2011). Entendimento corroborado por Vinnari e Skaerbaek (2014) segundo o desenvolvimento e aperfeiçoamento do quadro de gestão de risco envolvem investimentos, destacam que muitos dos gestores envolvidos nesse processo têm dúvidas graves sobre os custos envolvidos na gestão do risco em relação à sua utilidade. Não distante desses entendimento, as políticas públicas também podem ser uma barreira a implantação de 
SCI. Trosa (1999), citado por Dalglehish e Cooper (2005), aponta que o problema consiste em, por vezes, escolher entre as políticas públicas e o desempenho da organização, pois as decisões podem afetar a quantidade e a qualidade dos serviços.

Já Roberts e Candreva (2006) apontam que as falhas de monitoramento e verificação da eficácia de controles existentes dificulta não só a implantação de novos controles como melhorias dos já existentes. Também destacam que práticas contábeis inadequadas são uma barreira para o SCI no setor público. Leung e Isaacs (2008) relatam como relevante criar um processo que defina os objetivos do negócio, avalie os riscos, projete e implementa controles de risco, medidas de desempenho e continuamente monitore o SCI.

\section{Conclusão}

O objetivo deste estudo foi realizar uma análise das finalidades e da importância do controle interno no setor público e das barreiras para sua implantação. A contribuição teórica pretendida foi constituir um quadro referencial dos principais objetivos do controle interno, de sua importância e barreiras para implantação no contexto brasileiro, avançando nos estudos já realizados nesse sentido, fazendo a triangulação entre a legislação e os normativos em vigor, e a literatura que aborda o tema e apontamentos do TCU e da CGU.

A análise da estrutura do SCI, no contexto do Brasil, permitiu identificar que ele deve estar presente em todo o segmento público, sendo mais que uma necessidade para a gestão, uma obrigatoriedade legal. Esse quesito da legalidade é destacado por autores como Marçola (2014). No Brasil, existe um marco legal que regula o funcionamento do controle interno com seus objetivos bem definidos que podem estar relacionados a atender a uma lei específica, como no caso da LRF, ou para atender aos órgãos de controle externo na sua missão institucional. Isso foi apresentado e discutido de forma ampla nos tópicos 2.3 e 2.4. O Quadro 4 apresentou uma comparação entre as irregularidades encontradas na LFR e as falhas no SCI.

Devido a essa relevância, o CFC emitiu normativo que regra a relação do controle interno com a contabilidade. Ao analisar os objetivos presentes na Constituição Federal, nas NBCASPs e na literatura por meio do apresentado por Silva, Perez Júnior e Oliveira (2002), Mattos e Mariano (2009) e Pereira (2009), pode-se identificar a existência de onze objetivos de um SCI bem definidos, sendo eles: proteção de ativos, obtenção de informações apropriadas, apoio da eficiência operacional, potencialização do êxito do processo decisório, indução ao comportamento focado no resultado, garantia do respeito a normas e regulamentos da entidade (comportamento ético), comprovação da veracidade de informações contábeis e financeiras e operacionais, exercício do controle das operações de crédito, avais e garantias, bem como dos direitos e haveres dos órgãos públicos, apoio ao controle externo no exercício de sua missão institucional, apoio e controle da responsabilidade na gestão fiscal conforme a LRF e zelo pelo cumprimento das obrigações e prestação de contas.

Em relação à importância do SCI aplicado ao setor público, foram organizados em cinco categorias, como detalhado no Quadro 6: gestão do risco, informação, comportamento ético, imagem da entidade, proteção dos recursos públicos que foram originadas da triangulação entre a legislação em vigor, da revisão sistemática da literatura e dos apontamentos do TCU. Essa categorização foi fundamentada na abordagem realizada por autores como Kim (2004), Roberts e Candreva (2006), Dragija, Hladika, \& Vasicek, (2010), Popescu e Dascalu, (2012), Vijayakumar \& Nagaraja (2012), Simona e Gheorghe (2012), 
Vinnari e Skaerbaek (2014), Dalgleish e Cooper (2005), Wood (2009), Leung e Isaacs (2008). O estudo permite concluir que a premissa levantada de que o controle interno é importante no contexto do setor público é verdadeira, não só como forma de apoiar a gestão, mas como elemento de mudança na realidade do setor que carece de melhorias. Pode-se concluir que sua implantação é de grande relevância para melhoria dos resultados obtidos, da informação gerada, da imagem da organização.

As principais barreiras identificadas são a falta de uma cultura e gestão ao risco, alinhada com a carência de pessoal em número adequado e com a qualidade técnica exigida, bem como com as dificuldades e barreiras que o próprio exercício da função público pode ter inserido nesse contexto, como as limitações legais e o atendimento de políticas públicas. Essas barreiras foram apresentadas e discutidas no seção 4.4, sendo que foram definidas tendo por fonte as argumentações de Dalgleish e Cooper (2005) Azevedo, Ensslin e Reina (2010), Wood (2009), Farias, Luca e Machado (2010), Leung e Isaacs (2008), Mattos e Mariano (2009), Roberts e Candreva (2006), Dragija, Hladika, e Vasicek, (2010), Petrovits, Shakespeare e Shih (2011), Vinnari e Skaerbaek (2014). Entende-se que o setor público tem um grande caminho a percorrer no que diz respeito à cultura de controle interno e na comunicação deste para seus funcionários, bem como na valorização por parte dos gestores do SCI e da gestão e risco.

Este estudo teve como limitador o fato de não ter sido encontrado estudos empíricos internacionais que retratassem a realidade do setor público no contexto brasileiro, ficando limitada essa abordagem a estudos realizados em órgãos internacionais do Quadro 5 e a artigos publicados em periódicos nacionais. Sugere-se a realização de pesquisas na forma de questionários aplicados a gestores públicos que explorem elementos como o entendimento ou o grau de relevância dos objetivos, categorias de importância e barreiras de implantação do SCI no setor.

\section{Referências}

ALBUQUERQUE, J. M. Avaliação dos controles internos de uma instituição pública de ensino superior à luz da metodologia MCDA-Construtivista. Revista Contemporânea em Contabilidade, v. 8, n. 15, p. 129-150, 2011.

AZEVEDO, N. K.; ENSSLIN, S. R.; REINA, D. R. M. Controle Interno e as Fundações de apoio à pesquisa universitária: uma análise do funcionamento do Controle Interno nas Fundações da Universidade Federal de Santa Catarina no ano de 2010. Enfoque: Reflexão Contábil, v. 29, n. 3, p. 34-45, 2011.

BRASIL. Lei n. 4.320. Estatui normas de Direito Financeiro e para elaboração e controle dos orçamentos e balanços da União, dos estados, dos municípios e do Distrito Federal. Brasília, DF, de 17 de março de 1964. Disponível em http://www.planalto.gov.br/ccivil_03/leis/14320.htm. Acesso em 4 de junho de 2014.

Constituição Federal. Brasília, DF, de 5 de outubro de 1988. Disponível em http://www.planalto.gov.br/ccivil 03/constituicao/constituicao.htm. Acesso em 4 de junho de 2014. 
Lei Complementar n. 101. Brasília, DF, de 4 de maio de 2000. Estabelece normas de finanças públicas voltadas para a responsabilidade na gestão fiscal e dá outras providências. Disponível em http://www.planalto.gov.br/ccivil_03/leis/lcp/lcp101.htm. Acesso em 4 de junho de 2014.

Instrução Normativa do Departamento do Tesouro Nacional nº 16 de 20 de dezembro de 1991. Disponível em http://www.cgu.gov.br/sobre/legislacao/arquivos/instrucoes-normativas/in-01-06042001.pdf. Acesso em 4 de junho de 2014.

CONSELHO REGIONAL DE CONTABILIDADE. Aprova a NBC T 16.8 - Controle Interno. Resolução n. 1.135, de 25 de novembro de 2008.

CABRAL, R. A.; RIBEIRO, M. A. Análise dos apontamentos do TCE-MT nas contas públicas dos municípios da região médio norte do mato grosso. Revista UNEMAT de Contabilidade, v. 1, n. 2, p. 17-21, 2012.

CAMPBELL, D. R.; CAMPBELL, M.; ADAMS, G. W.. Adding Significant Value with Internal Controls. CPA Journal, v. 76, n. 6, Jun. 2006.

CAVALCANTE, D. S.; PETER, M. D. G. A.; MACHADO, M. V. V.. Organização dos órgãos de controle interno municipal no estado do ceará: um estudo na região metropolitana de fortaleza. ASAA-Advances in Scientific and Applied Accounting, v. 4, n. 1, p. 24-43, 2013.

CAVALHEIRO, J. B.; FLORES, P. C.. A organização do sistema de controle interno municipal. $C R C / R S, 2007$.

CONTROLADORIA GERAL DA UNIÃO. Prestação de Contas da Presidência da República, disponível em http://www.cgu.gov.br/assuntos/auditoria-e-fiscalizacao/avaliacao-da-gestaodos-administradores/prestacao-de-contas-do-residente-da-republica. Acesso em 4 de junho de 2014.

COSO, Committee of Sponsoring Organizations of the Treadway Commission, Controle Interno, Estrutura Integrada, Sumário Executivo. Disponível em http://www.pwc.com.br/pt_BR/br/auditoria-interna/assets/coso-13.pdf acesso em 4 de junho de 2014.

DENZIN, N. K.. The research act: A theoretical introduction to sociological methods. Transaction publishers, 1970.

DRAGIJA, M.; HLADIKA, M.; VASICEK, V.. Impact of Public Internal Financial Control on Public Administration in Croatia. Theoretical and Applied Economics, v. 4, n. 4, p.71, 2010. 
DALGLEISH, F.; COOPER, B. J.. Risk Management: Developing a framework for a water authority Management of Environmental Quality, v.16, n.3, p. 235-249, 2005.

DAVIS, M. D.; BLASCHEK, J. R. D. S.. Deficiências dos sistemas de controle interno governamentais atuais em função da evolução da economia. In: CONGRESSO USP DE CONTROLADORIA E CONTABILIDADE, v. 6, 2006.

MATTOS, C C.; MARIANO, R. P.. Controle interno: uma abordagem teórica. Contabilidade Vista \& Revista, v. 10, n. 1, p. 34-39, 2009.

LIMA, G. C.; MIRANDA, L. C.; VASCONCELOS, M. T. D. C.; OLIVEIRA, R. R.. Avaliação das normas editadas pelos tribunais de contas brasileiros para orientar os poderes municipais na institucionalização dos sistemas de controle interno. Registro Contábil, v. 5, n. 1, p. 20-34, 2014.

FARIAS, R. P.; LUCA, M. M. M.; MACHADO, M. V. V.. A metodologia COSO como ferramenta de gerenciamento dos controles internos. Contabilidade, Gestão e Governança, v. 12, n. 3, p. 55-71, 2010.

FRANCO, H.; MARRRA, E.. Auditoria contábil: normas de auditoria, procedimentos e papéis de trabalho, programas de auditoria e relatórios de auditoria. 2. ed. São Paulo: Atlas, 1991.

GERIGK, W.; CLEMENTE, A.; RIBEIRO, F.. O padrão do endividamento público nos municípios brasileiros de porte médio após a lei de responsabilidade fiscal. Revista Ambiente Contábil, v. 6, n. 1, p. 122-140, 2014.

GODOY, A. S.. Refletindo sobre critérios de qualidade da pesquisa qualitativa. GESTÃO. Org-Revista Eletrônica de Gestão Organizacional, v. 3, n. 2, p. 79-89, 2005.

INTOSAI. Guidelines for Internal Controls Standards for the Public Sector. 2004. disponível em http://www.issai.org/media/13329/intosai gov 9100 e.pdf. Acesso em 3 de maio de 2014.

IMONIANA, J. O.; NOHARA, J. J.. Cognição da estrutura de controle interno: uma pesquisa exploratória. Revista de Administração e Contabilidade da Unisinos, v. 2, n. 1, p. 37-46, 2005.

JORDÃO, R. V. D.; SOUZA, A. A.; TEDDO, A. C.. Governança Corporativa e Ética de Negócios: Uma análise nos principais modelos internacionais de controle interno. Sistemas \& Gestão, v. 7, n. 1, p. 76-92, 2012.

JOSÉ FILHO, A.. A importância do controle interno na gestão pública. Revista Diversa, v. 1, n. 1, p. 85-99, 2008. 
KADAMA, F. R. K.. Crafting a strategy for improved communal waste management in mafikeng. International Journal of Sustainable Development and Planning, v. 8, n. 1, p. 20-35, 2013.

KIM, E. S.. How did enterprise risk management first appear in the Korean public sector? Journal of Risk Research, v. 17, n. 2, p. 263-279, 2014.

LÉLIS, D. L. M.; MÁRIO, P. D. C.. Auditoria interna com foco em governança, gestão de riscos e controle interno: análise da auditoria interna de uma empresa do setor energético. In: CONGRESSO USP DE CONTABILIDADE, 9º 2009.

LEUNG, F.; ISAACS, F.. Risk management in public sector research: approach and lessons learned at a national research organization. R\&D Management, v. 38, n. 5, p. 510-519, 2008.

MARÇOLA, C.. Auditoria interna como instrumento de controle social na administração pública. Revista do Serviço Público, v. 62, n. 1, p. 75-87, 2014.

MELO, E. A. D.; MONTEIRO, A. D. O.; FADUL, É.. Controle do Gasto Público e Responsabilidade Fiscal: o Caso da Administração Municipal de Salvador. Organizações \& Sociedade, v. 14, n. 41, p. 161-175, 2007.

MOZZATO, A. R.; GRZYBOVSKI, D.. Análise de conteúdo como técnica de análise de dados qualitativos no campo da administração: potencial e desafios. Revista de Administração Contemporânea, v. 15, n. 4, 731-747, 2011.

OLIVEIRA, J. C. R. D.. O papel do controle interno na prevenção de erros e fraudes: um estudo de caso em cooperativa de crédito de Minas Gerais. In: CONGRESSO USP DE INICIAÇÃO CIENTÍFICA EM CONTABILIDADE, v. 8, 2011.

PETROVITS, C.; SHAKESPEARE, C.; SHIH, A.. The causes and consequences of internal control problems in nonprofit organizations. The Accounting Review, v. 86, n. 1, p. 325-357, 2011.

PEREIRA, A. N.. Controles Internos Empresariais e Gestão: Visões e Importância-Uma Abordagem Exploratória. Contabilidade Vista \& Revista, v. 15, n. 3, p. 27-44, 2009.

POPESCU, M.; DASCĂLU, A.. The internal control system within universities. The need for management training for Romanian hospital, v. 5, n. 54, p. 101, 2012

RAUPP, F. M.; BEUREN, I. M.. Metodologia da pesquisa aplicável às ciências sociais. Como elaborar trabalhos monográficos em contabilidade: teoria e prática. São Paulo: Atlas, 76-97, 2003.

ROBERTS, N.; CANDREVA, P. J.. Controlling internal controls. Public Administration Review, v. 66, n. 3, p. 463-465, 2006. 
SACRAMENTO, A. R. S.. Contribuições da Lei de Responsabilidade Fiscal para o avanço da accountability no Brasil. Cadernos Gestão Pública e Cidadania, v. 10, n. 47, p. 20-48, 2005.

SARENS, G.; VISSCHER, C.; VAN GILS, D.. Risk Management and Internal Control in the Public Sector: An In-Depth Analysis of Belgian Social Security Public Institutions. Bulletin de documentation/Service public fédéral finances, v. 70, n. 3, p. 65-90, 2010.

SAUR-AMARAL, I.. Towards a Methodology for Literature Reviews in Social Sciences, 2011.

SIENA, O.; SOARES, I. S.. Característica de gestão e do controle em uma universidade pública federal: uma análise de documentos oficiais. Revista de Administração e Negócios da Amazônia, v. 3, n. 3, p. 1-19, 2012.

SILVA, C. A. S.; OLIVEIRA, L. M.; PEREZ JR., J. H.. Controladoria estratégica. São Paulo: Atlas, 2002.

SILVA, W. A. C.; ROCHA, A. M.; MELO, A. A. O.. Sistema de gerenciamento e controle interno: uma análise dos escritórios de contabilidade de Belo Horizonte/MG e região metropolitana a partir da Taxonomia de Kaplan e Cooper. Revista de Contabilidade e Organizações, v. 5, n. 11, p. 125-144, 2011.

SIMONA, G. D.; GHEORGHE, T. I.. Court of auditors-the assessment of internal control system in the public sector in Romania. Case study bihor county. Annals of Faculty of Economics, v. 1, n. 1, p. 925-930, 2012.

THOMÉ, V. A.; TINOCO, J. E. P.. A existência do Controle Interno como auxílio à governança para gerar informações aos stakeholders das entidades públicas: a realidade em 20 prefeituras do estado do Paraná-Brasil. In: CONGRESSO USP DE CONTROLADORIA E CONTABILIDADE. São Paulo. v. 5, 2005.

TRIBUNAL DE CONTAS DA UNIÃO. Critérios Gerais de Controle Interno na Administração Pública. Um estudo dos modelos e das normas disciplinadoras em diversos paises. Disponivel em: http://portal2.tcu.gov.br/portal/pls/portal/docs/2056688.pdf. Acesso em 12 de junho de 2014.

VIJAYAKUMAR, A. N.; NAGARAJA, N.. Internal Control Systems: Effectiveness of Internal Audit in Risk Management at Public Sector Enterprises. BVIMR Management Edge, v. 5, n. 1, p. 1-8, 2012.

VINNARI, E.; SKAEBAEK, P.. The uncertainties of risk management: A field study on risk management internal audit practices in a Finnish municipality. Accounting, Auditing \& Accountability Journal, v. 27, n. 3, p. 489-526, 2014. 
WOODS, M.. A contingency theory perspective on the risk management control system within Birmingham City Council. Management Accounting Research, v. 20, n. 1, p. 69-81, 2009. 